LA-3754

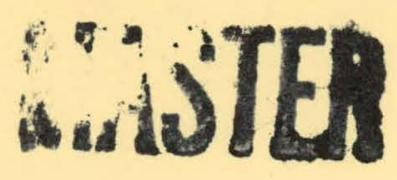

\title{
LOS ALAMOS SCIENTIFIC LABORATORY of the
}

University of California

LOS ALAMOS - NEW MEXICO

\author{
The 1965 ARPA-AEC Joint Lightning Study \\ at Los Alamos \\ Volume I
}




\section{DISCLAIMER}

This report was prepared as an account of work sponsored by an agency of the United States Government. Neither the United States Government nor any agency Thereof, nor any of their employees, makes any warranty, express or implied, or assumes any legal liability or responsibility for the accuracy, completeness, or usefulness of any information, apparatus, product, or process disclosed, or represents that its use would not infringe privately owned rights. Reference herein to any specific commercial product, process, or service by trade name, trademark, manufacturer, or otherwise does not necessarily constitute or imply its endorsement, recommendation, or favoring by the United States Government or any agency thereof. The views and opinions of authors expressed herein do not necessarily state or reflect those of the United States Government or any agency thereof. 


\section{DISCLAIMER}

Portions of this document may be illegible in electronic image products. Images are produced from the best available original document. 


\section{LEG A L NOTICE}

This report was prepared as an account of Government sponsored work. Neither the United States, nor the Commission, nor any person acting on behalf of the Commission:

A. Makes any warranty or representation, expressed or implied, with respect to the accuracy, completeness, or usefulness of the information contained in this report, or that the use of any information, apparatus, method, or process disclosed in this report may not infringe privately owned rights; or

B. Assumes any liabilities with respect to the use of, or for damages resulting from the use of any information, apparatus, method, or process disclosed in this report.

As used in the above, "person acting on behalf of the Commission" includes any employee or contractor of the Commission, or employee of such contractor, to the extent that such employee or contractor of the Commission, or employee of such contractor prepares, disseminates, or provides access to, any information pursuant to his employment or contract with the Commission, or his employment with such contractor.

This report expresses the opinions of the author or authors and does not necessarily reflect the opinions or views of the Los Alamos Scientific Laboratory.

Printed in the United States of America. Available from Clearinghouse for Federal Scientific and Technical Information National Bureau of Standards, U. S. Department of Commerce

Springfield, Virginia 22151

Price: Printed Copy $\$ 3.00$; Microfiche $\$ 0.65$ 
This report was prepared as an account of Government sponsored work. Neither the United A. Makes anymission, nor any person acting on behalf of the Commission;

UC-34, PHYSICS

racy, completeness or of any information, apparatus, method information contained in this report, or that the use privately owned rights; or

Be of any information apparatus, respect to the use of, or for damages resulung from the

AB lation, apparatus, method, or process disclosed in this report.

ployee used in the above, "person acting on bebalf of the finmmission" includes any einploye or contractor of the commission, or employee of such contractor, to the extent Whe Commission, or employee of such contractor prepar

with the Commisglon or hiccess to, any information pursuant to his employment or contract

TID -4500

\section{LOS ALAMOS SCIENTIFIC LABORATORY of the \\ University of California \\ LOS ALAMOS - NEW MEXICO}

Report written: May 1967

Report distributed: December 5, 1967

\section{The 1965 ARPA-AEC Joint Lightning Study}

at Los Alamos*.

Volume I

The Lightning Spectrum. Charge Transfer in Lightning.' Efficiency of Conversion of Electrical Energy into Visible Radiation.

by

T. Robert Connor

*Work done under the auspices of the $\mathrm{AEC}$ in response to ARPA Order No. 631, Program Code No. 5820 
COMTENTS

VOLUME $I^{*}$.

Abstract

Page

I. Introduction

II. Spectroscopy of Ifightning . 5

A. Apparatus . . . . 5

B. Calibration 5

C. Method of Data Reduction $\quad: \cdot: \cdot 6$

D. Results . 9

E. Discussion of Results . 9

F. Discrimination 27

III. Calculation from Electric Field Antenna Data of the Charge Transferred to Ground by Lightning

28

IV. Efficlency of Conversion of Electrical Energy Into V1sible Radiation in a Lighting Channel

Appendix. Atmospheric Transmission

Acknowledgments

References

* Other volumes covering different aspects of the 1965 ARPA-AEC Joint Llghtning Study at Los Alamos are:
IA-3755 Volume II. Comparison of the Lightning Spectrum with Narr ow-Field and All-Sky Photometer Data
IA-3756 Volume III. Propagation of L1ght 1nto All-Sky Detectors
IA-3757 Volume IV. Discrimination and False Alarm Analysis 
THE 1965 ARPA-AEC JOINT LIGHTNING STUDY AT LOS ALAMOS

VOLUME I

THE LIGHTNING SFECTRUM. CHARGE TRANSFER IN LIGHTNING. EFTICIENCY OF CONVERSION OF ELECTRICAL ENERCY INTO VISIBLE RADIATION

\author{
T. Robert Connor
}

ABSTRACT

In the summer of 1965 the Atomic Energy Cormission and the Department of Defense (ARPA) sponsored studies of the optical and electromagnetic emissions of lightning at Los Alamos, N. M., to obtain information for improving lightning discrimination methods in high altitude air fluorescence detection systems. The project was a coordinated effort among IASL, EG\&G, DRI, and a small AWRE team. IASL obtained slitless spectra of 11 strokes from six flashes. The analysis and evaluation of these spectra and correlated electric fleld data are the subject of this report.

The spectra were of the following types: (1) ten stroke-resolved spectra of first and subsequent return strokes, (2) time-resolved spectra of two continuing luminosities, (3) the spectrum at three different heights along the channel of a single return stroke. All are fully reduced in terms of flux (erg $\left./ \AA-\mathrm{cm}^{2}\right)$ at the entrance pupil of the spectrograph and corrected for atmospheric transmission. While not a large statistical sample, these spectra are of considerable value, for they are the only quantitatively reduced spectra covering the full visible wavelength range.

The spectrum of IIghtning consists of a strong continuum with strong lines attributable to NII, NI, HI, and OI. The spectra of first return strokes differ fran those of subsequent return strokes and continuing luminosities. If the best stralght-litne fit is made to the continuum, the ratios of continuum in the vicinity of $3900 \AA$ to that in the vicinity of $6900 \AA$ are $2.0,1.6$, and 1.0 for first return strokes, subsequent return strokes, and continuing luminosities, respectively. These ratios indicate decreasing channel temperatures in the order given. Also, if the ratio of NII radiation to NI radiation 18 used as a messure of excitation and 1on1zation, then first return strokes have the highest degree of excitation and Ionization of the three lightning phenomena, and continuing luminosities have the lowest.

On the bas1s of the 10 return-stroke spectra, considering atmospher1c transmission and photodetector sensitivities, the blend of NII multiplets at $5000 \AA$ and the $H \alpha$ line at $6563 \AA$ appear to be the most outstanding 
features with a potential for discrimination applications. Under a variety of storm and background light conditions, the 5000- $\AA$ feature may be even better than the $6563-\AA$ line.

The charge transferred to ground and the energy deposited in the channel were calculated using electromagnetic data and photographic rangIng data. Using data on 18 strokes from $31 x$ flashes, averages of charge transferred to ground are 7 coulombs/stroke, and 28 coulombs/flash. The energy per meter of channel deposited by a return stroke ranged between $2 \times 10^{4}$ and $3 \times 10^{5}$ joules/meter. The efficiency for the conversion of electrical energy to visible (3900- to $6900-\AA)$ radiation was calculated to be $0.7 \%$.

\section{INIRODUCTION}

During the 1965 ARPA-AEC joint lightning study at Los Alamos, coordinated data were obtalned from a time-resolved spectrograph, from collimated photometers with narrow spectral bandpasses, from all-sky photometers similar to those used in the IASI H1gh Altitude A1r Fluarescence Detection System, and from antennas designed to study the electromagnetic emisslons produced by lightning. The study was undertaken to obtain basic data on the physics of lightning and statistical information on 1ts optical and electromagnetic emissions to improve lightning discrimtinetion methods in Vele sierra systems. The results of the spectrographic and IASL electromagnet1c-pulse studies are discussed and applied to the problem of discrimination.

The literature on the optical spectrum. of lightning from 1901 to $1960^{2}$ shows that the spectra obtained by different techniques differ significantly in certain features of importance to designers 'of systems intended to detect high altitude air fluorescence from clandestine nuclear tests in space. Those Invest1gatiors, Incluaing Salanave, who employed slitless spectrogrephs, report a strong continuum throughout the visible wavelength range with strong line features from neutral and singly lonized atoms, In some cases with a wide water-vapor absorption band extending from 5900 to $6000 \AA$, and in a few (approximately 5\%) cases with weak $\mathrm{N}_{2}^{+}$in molecular-band emission. on the other hand, those who employ conventional slit spectrographs to obtain long
tIme exposures ( 1 to 2 hours) at night of all the light emitted by a lightning storm report that molecular bonds in general, and the $\mathrm{N}_{2}^{+}$IN bands in particular, are among the most dominant features in the visible spectrum. Since the detection of high altitude air fluorescence is based on a narrow optical bandwidth channel at the 3914- $\$$ bandhead of the $\mathrm{N}_{2}^{+}$IN $(0,0)$ transition, it is important to obtain answers to the following questions: (1) What is the source of molecular-band radiation in a lightning storm? (2) Is this source capable of triggerIng the all-sky air flucrescence detection system? (3) If this source can trigger the all-sky detection system, can the system be modifled to decrease the false alarm rate during lightning storms?

There are data in the literature which have a bearing on these questions. In 1903 Fox ${ }^{2}$ observed, from slitless spectra, that relative intensitios of various atomic line features in a lightning channel varied as a function of helght along the channe?. Then, in 1941, Israel and Wurm, ${ }^{3}$ using a slitless spectrograph, first made the now confirmed observation that the degree of Ionization and excitation as measured by the ratio of radiation from singly lonized atoms to that from neutral atoms is highest near the bottom of the lightning channel and decreases toward the cloud. They also identifled the $\mathrm{N}_{2}^{+} \mathrm{lN}$ bands whose excitation followed that of the neutral at ans and was therefore a stronger spectral feature nearer the clouds.

Meinel and Salanave have studied the posstble source of $\mathrm{N}_{2}^{+}$emission in lightning starms and 
limited the list of possiblilties to the following:

(1) continuing luminosity in the main channel,

(2) the presumed fan of streamers within the cloud that spread the charge pulse,

(3) leader processes, or

(4) corona, which emanates from a large area of the earth's surfece, and can proluce lang duration pulses with significant exposure in a time-integrated spectrum.

During the summer study, we obtained a number of time-resolved slitless spectra which were then fully reduced to give the incident, time-integrated, spectral flux (ergs/cm ${ }^{-2} \AA^{-2}$ ) at the entrance pupil of the spectrograph as a function of wavelength; these spectra were corrected for atmospheric transmission. In a search of the literature no other fully reduced spectra of lightning were found.

Th1s report discusses these spectrographic data and the IASL electromagnet ic pulse data in an attempt to answer some of the questions posed here and to extract a few more numbers to add to the meager supply of quantitative results on the physics of lightning.

\section{SPECTROSCOPY OF IIGHTNING}

\section{A. Apparatus}

The reduced spectra were obtalned using the N4GS lens and grating siltless spectrograph ${ }^{5}$ with film-aperture ratio of $f / 2.8$ and dispersion of ap-

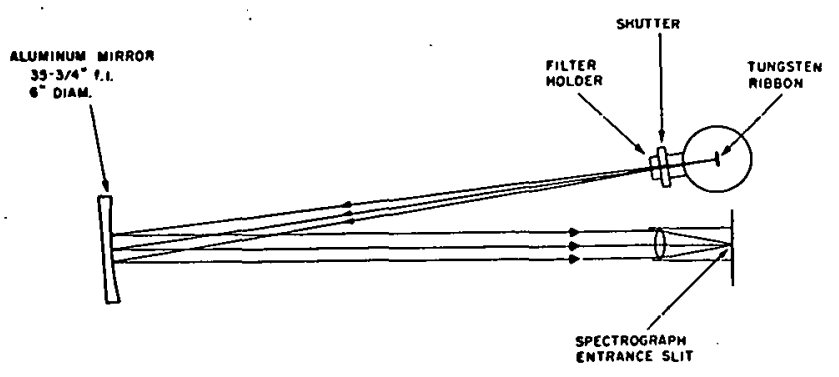

F1g. 2. Celibration setup for N4GS spectrograph.

proximately $90 \mathrm{~A} / \mathrm{m}$. Figure 1 is a diagram of the N4GS optics. A measured resolution of about 6 was realized. Spectra covered the wavelength interval 3800 to 7000 A. A horizontal slot at the normal slit plane defined the fleld of view to either $0.05^{\circ}$ or $0.3^{\circ}$ vertical by $16^{\circ}$ horizontal (total angles). Time resolution, attained by film motion perpendicular to the direction of dispersion, was either 3 or 18 msec. The film used was Eastman Kodak 2475.

\section{B. Callbration}

Flgure 2 shows the setup of the calibration source. The tungsten ribbon was placed at the focus of the aluminum mirror, and the focus was checked with a theodollte. The image of the ribbon was then formed at the entrance slit by an objective lens and centered on the 100 $\mu-w 1 d e$ vertical slit used for callbration. The shitter open time was measured by placing a phototube inside the spectrograph at the plane A-A (Fig. 1) and displaying the signal on an

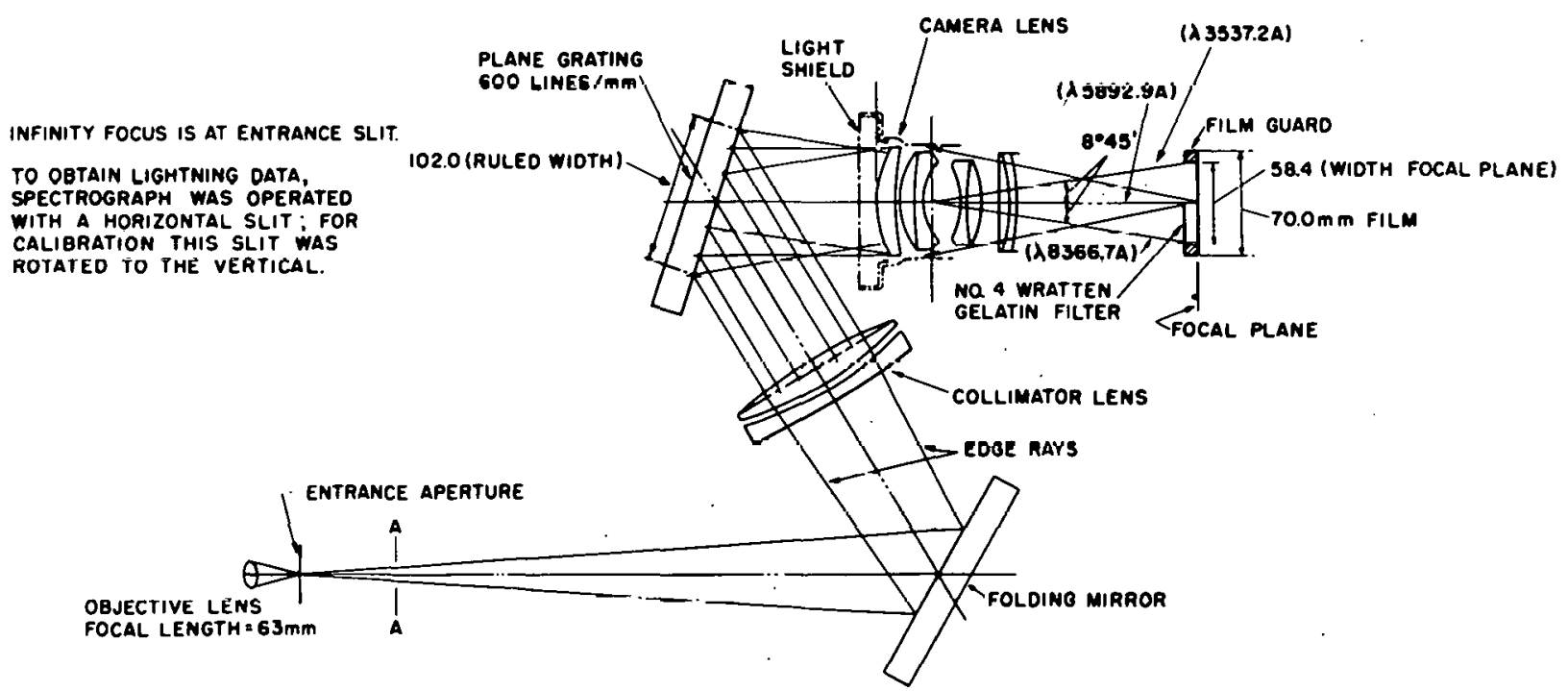

F1g. 1. Optics of the N4GS spectrograph. 
oscilloscope. Spectra of the tungsten filament were then recorded on film for various combinations of callbrated neutral density filters. A wavelength callbration was obtained by taking spectra of a mercury and a neon source. Sensitometric step wedges were impressed on the $\mathrm{ftlm}$ which was then developed by a Versomat film processor.

The temperature of the tungsten filament wos measured with a pyrometer and determined to be $2024.4^{\circ} \mathrm{K}$. The brightness vs wavelength curve for the tungsten lamp was determined using W. Gould's RAY code.

A transmission, $T(\lambda)$, was calculated at $100-\AA$ Intervals between 3800 and $7200 \AA$ for each f1lter combination. This transmission is multiplied by the brightness, $B(\lambda)$, of the tungsten lamp and by the exposure duration, $\tau$, and divided by the product of dispersion, $D$, and the width, $W$, of the entrance slit in the $111 \mathrm{~m}$ plane to give the time-integrated brightness, $\operatorname{INIB}(\lambda)$, of the Image in the entrance slit,

$$
\operatorname{INTB}(\lambda)=[B(\lambda) \cdot T(\lambda) \cdot \tau] / D \cdot W \frac{\text { ergs }}{c^{2} \cdot \AA \cdot s r},
$$

for an entrance-slit width corresponding to $1 \AA$ in the film plane.

For the presentation of the data in final form, this brightness at the entrance slit is converted to flux at the entrance pupil.

\section{Method of Data Reduction}

The densitometry was carried out on the Eastman Kodak mlcrodensitometer. The slit chosen was $25 \mu$ high (the spectra ranged between 50 and $300 \mu$ in height) and $150 \mu$ wide (equivalent to $13.5 \AA$ ). Although the the cretical resolution of $3 \AA$ for the spectrograph would have dictated the use of a slit approximately $30 \mu$ wide, it was neeessary to use the wider slit to lessen the nolse in the densitometer tracing, since this noise was due to the graininess of the f1lm. The densitometer was callbrated daily using a step wedge as a standard.

The densftometer tracings of the spectra were digitized and put on IBM cards, and the data reduc$t i o n$ was carried out by a series of computer programs. A description of the data reduction of one of the spectra is given to 1llustrate the steps taken. The spectrum is that of a return stroke of flash number 103 of run 40 (hereafter referred to by Count No. 40.103), wh1ch was the stroke on wh1ch the photolectric systems triggered. This was the secand stroke of a miltistroke cloud-to-ground flash.

Figure 3 is a plot of density vs wavelength for the daylight exposure taken milliseconds before flash 40.103. Three separate tracings were made milliseconds apart and hand averaged on a light table. The dots in Fig. 3 represent these averaged daylight background data. The solid line is the data corrected by the step-wedge callbration of the densitometer.

The solid line in Fig. 4 is the densitometer tracing (corrected by step-wedge callbration) of the stroke which occurred at the time of the trigger for flash 40.103 .

The densitometer tracings are reduced using the callbrations described in Section B. The results for the daylight background and the lightning spectrum are shown in Flgs. 5 and 6 , respectively. The wavelength scale has also been corrected at this point.

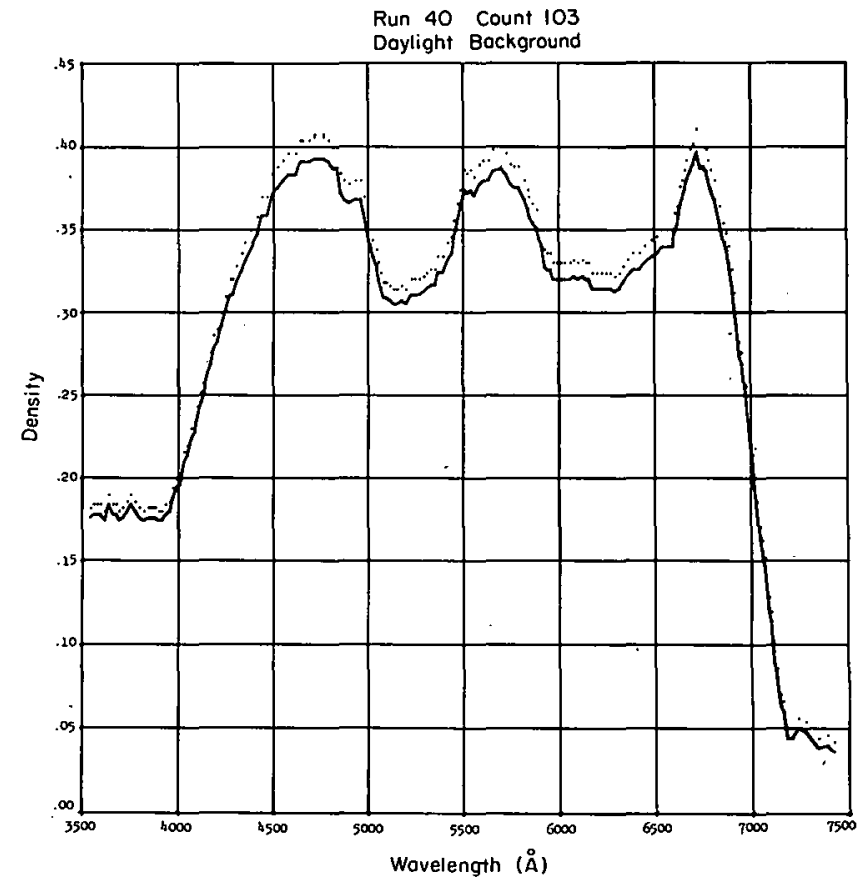

Fig. 3. Density vs wavelength produced by daylight background millisecands before count 103, run 40. Zero density equals film fog level. 


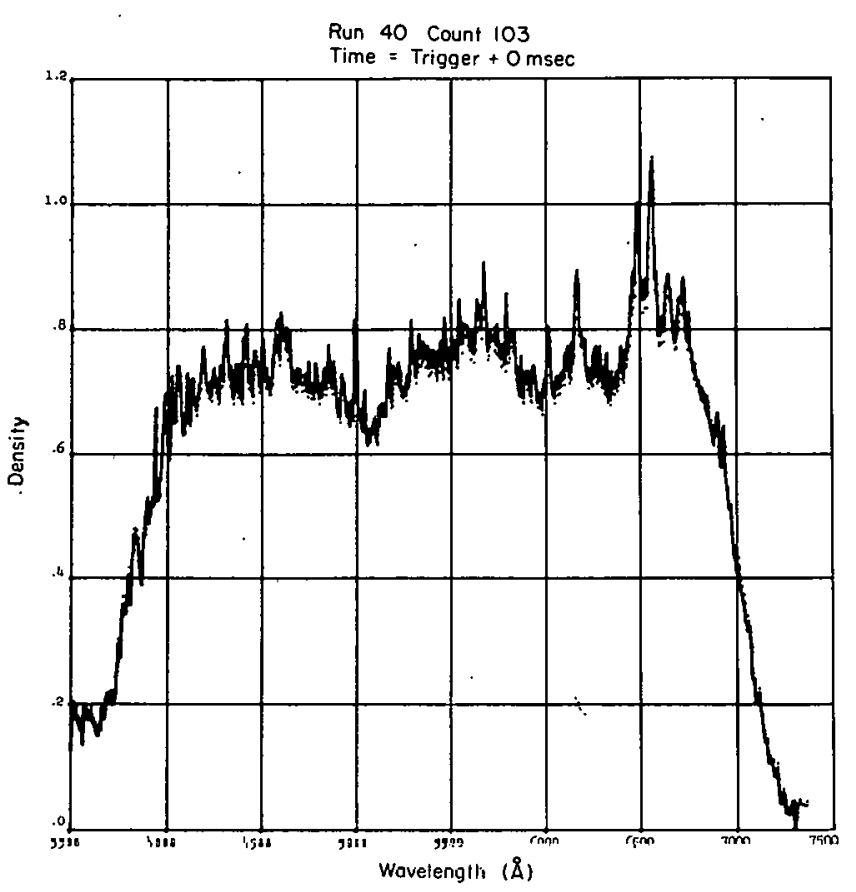

Fig. 4. Density vs wavelength produced by lightning strokes plus daylight background. Zero density equals film fog level.

Figure 7 shows the result of subtracting the daylight background from the lightning spectrum.

Figure 8 is the humidatr transmission under Los Alamos weather conditions. (For discussion of atmospheric transmission see the Append $1 x_{0}$ ) Finsl-

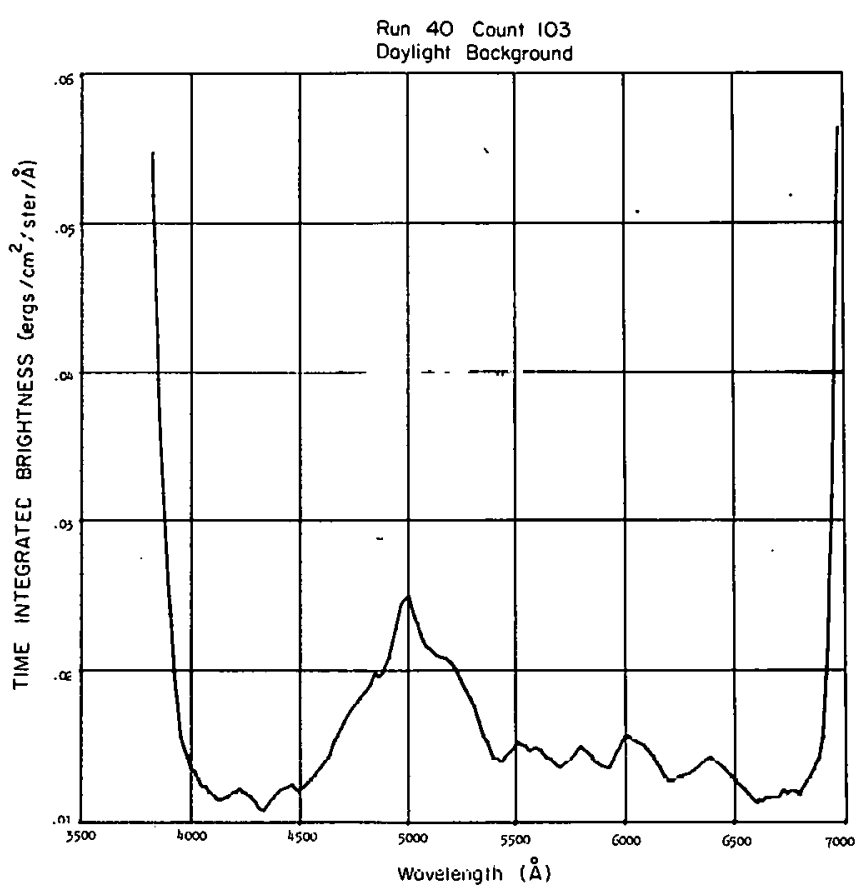

F1g. 5. Inferred daylight background spectrum with wavelength scale corrected.

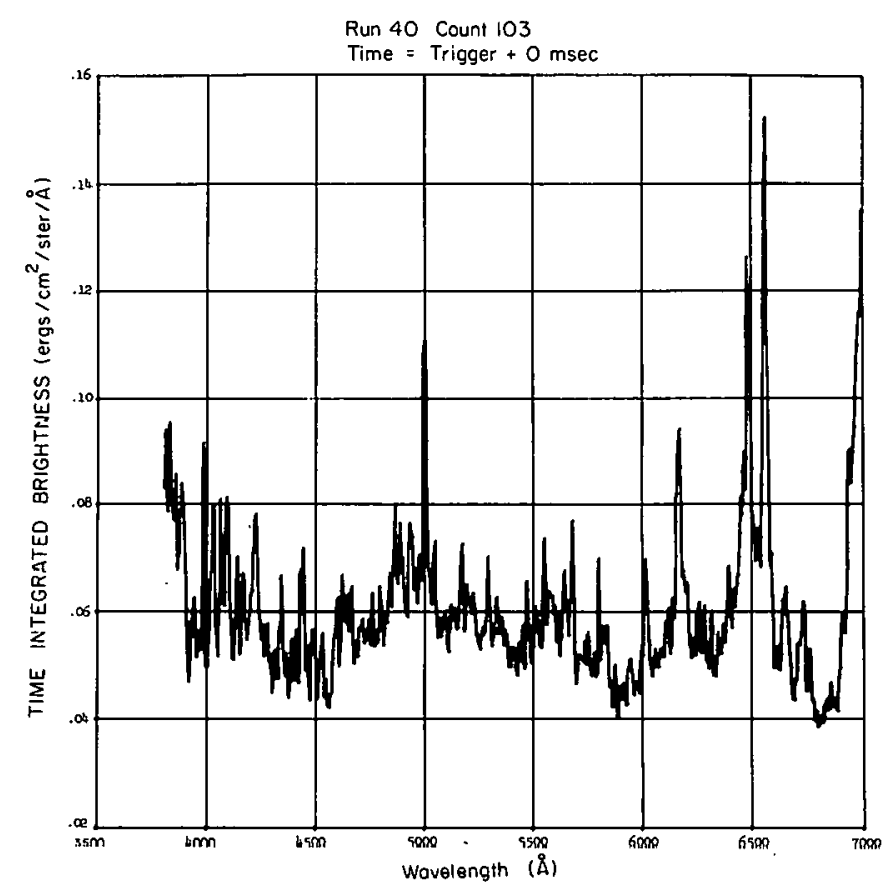

Flg. 6. Lightning spectrum plus inferred daylight spectrum with wavelength scale corrected.

ly, the spectrum is corrected for humid-air transmission (see F1g. 11), and the dominant radiating species are 1dentified using Charlotte Moore's multiplet designations ${ }^{B}$ which are given in Table $I$.

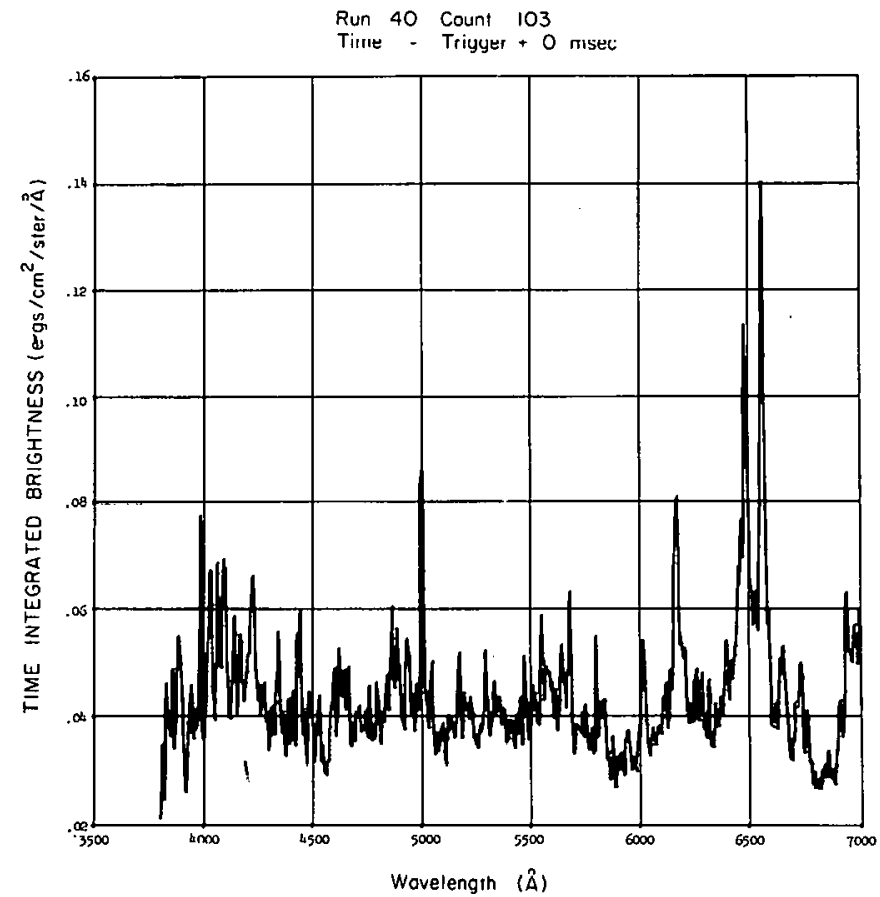

F18. 7. Spectrum of lightning expressed as brightness vs wavelength of channel image at spectrograph entrance slit. 
Table I. Multiplet Designations

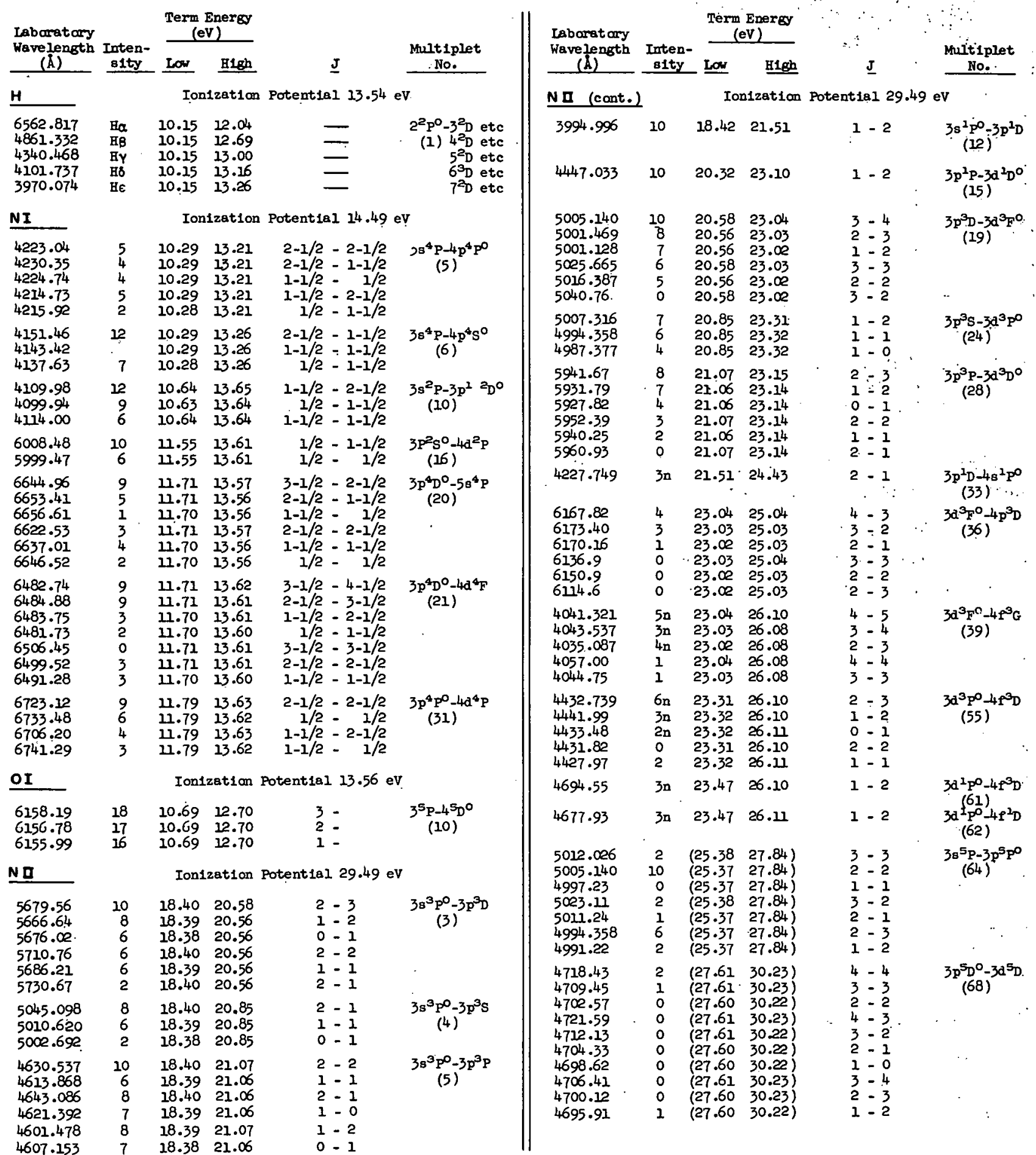




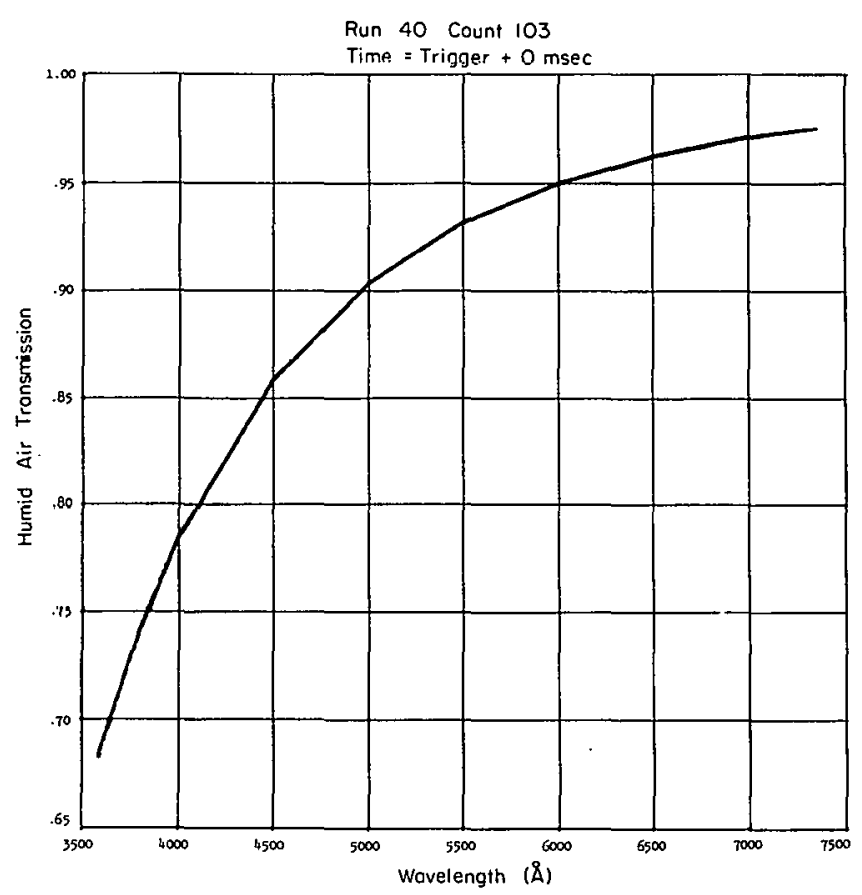

Fig. 8. Humid-air transmission for 7-km observetion path under Los Alamos weather conditions.

\section{Results}

The results are presented here in the form of fully reduced spectra whose strongest and most reproducible (frum stroke to stroke) features are 1dentified. These spectre are presented 1n Figs. 9 through 25 as plots of wavelength vs time-integrated fjux at the entrance pupil of the spectrograph. Each is identified by a run and count number. The time given is that at which the spectrum was obtained measured relative to the trigger provided by the collimated photolectric $\mathrm{H} \alpha$ channels. The recards of the Los Alamos weather station were used to calculate the atmospheric selective transmission as described in the Appendix. The range of the stroke was measured by photographic triangulation. ${ }^{7}$ The spectral flux is integrated over wavelength from 3900 to $6900 \AA$, and after rain transmission correction this result is used to calculate the efficiency of conversion of electrical energy to visible radiation in the channel.

It must be potated out that the time-integrated flux is that originating from a length of channel whose vertical component is $l$. The vertical length of the channel over which the spectrum is spatially integrated is dependent on range and is given by $\ell=0.9 \mathrm{R}$ meters, where $\mathrm{R}$ is the range in kilometers.

Spectra were obtained for first return strokes, subsequent return strokes, and continuing luminosities.

\section{E. Discussion of Results}

In the data reduction the most difficult problem was to prove that the continuum, inferred from the slitless spectra, was indeed true continuum and not scattered light. 8 This problem was solved during the summer of 1966 by operating the same spectrograph as a time-resolving slit instrument. On the whole, the slit and slitless spectra show features similar to those described above. While the results of the slit spectra are still preliminary, I can make the following statements regarding the two types of spectra:

(1) Ne1ther the time-resolved siltless spectra nor the time-resolved slit spectra show a bandhead at $3914 \AA$.

(2) For the slitless spectra, the image of the lightning channel at the entrance aperture may, indeed, be regarded as the entrance sl1t; $1 . e$. the spectra presented here are free from errors due to light scattered from points at large angular distances from the channel. This conclusion is drawn from the structural similarity of continua of the slit and slitless spectra in those intervals (3800 to $4000 \AA, 4800$ to $5200 \AA$, and 6800 to $7000 \AA$ ) In which the spectrograph-film sensitivity is changing quickly as a function of wavelength.

(3) Linewidths for the slit spectra are narrower than those for the slitless spectra. This may be due to light scattered, reflected, or emitted close to the channel or to light scattered at small angles near the propagation path to the detector. However, such scattering is not sufficient at large distances from the channel to contradict conclusion (2), and limits the interpretation of the slitless spectre only insofar as it prevents the inference of linewidths from them.

The slitless spectra may be classified as: (1) first return strokes, (2) subsequent return strokes, and (3) continuing luminosities, each with different spectral characteristics. The descriptions of each follow. 


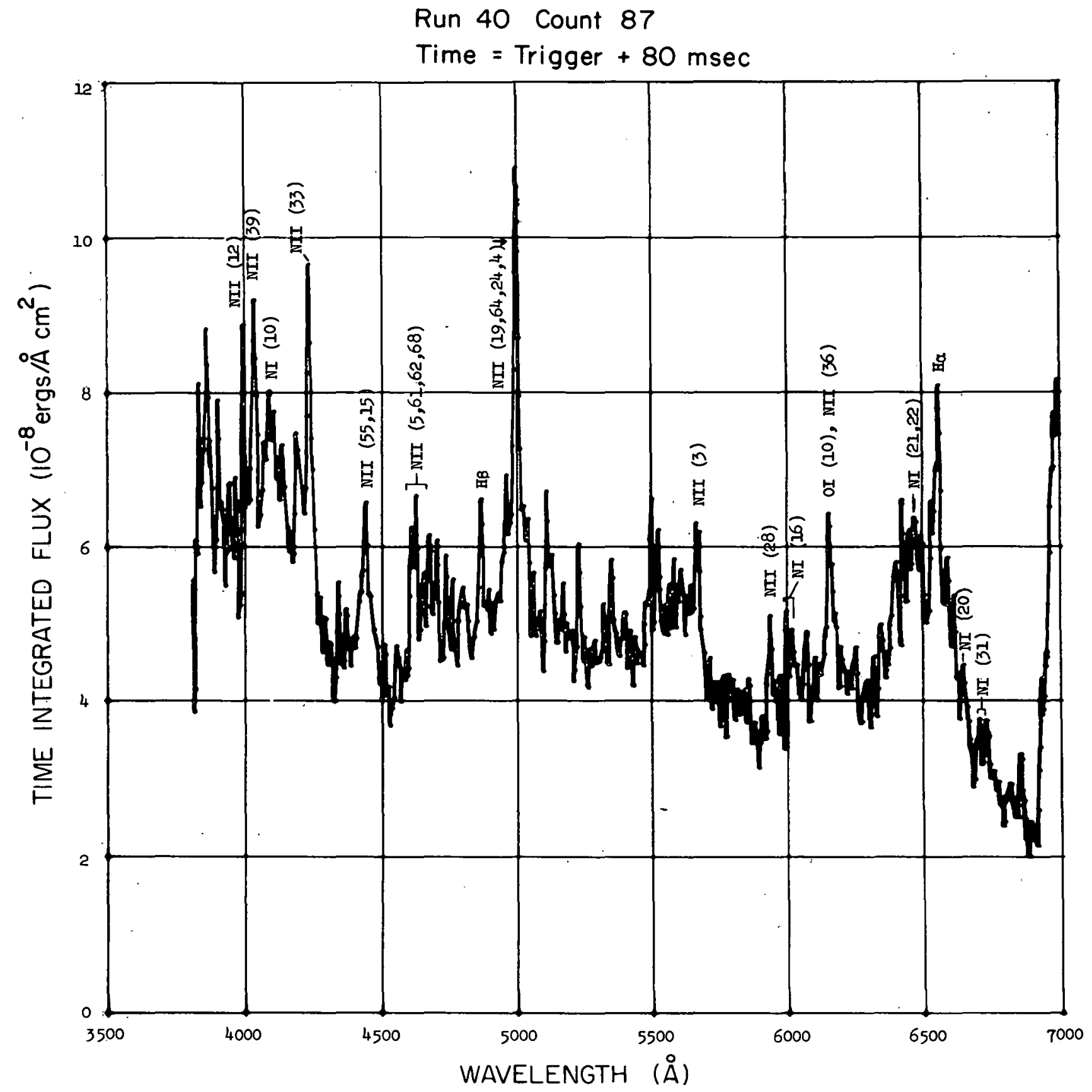

F1g. 90 Spectrum (taken at twilight) of first return stroke. Electrical energy deposited $=3.3 \times 10^{5}$ joule/meter. Rainfali transmission $=8.7 \times 10^{-3}$. Visible energy radiated $=2.0 \times 10^{3}$ joule/meter, corrected for rainfall transmission. Range $=10 \mathrm{~km}$. 


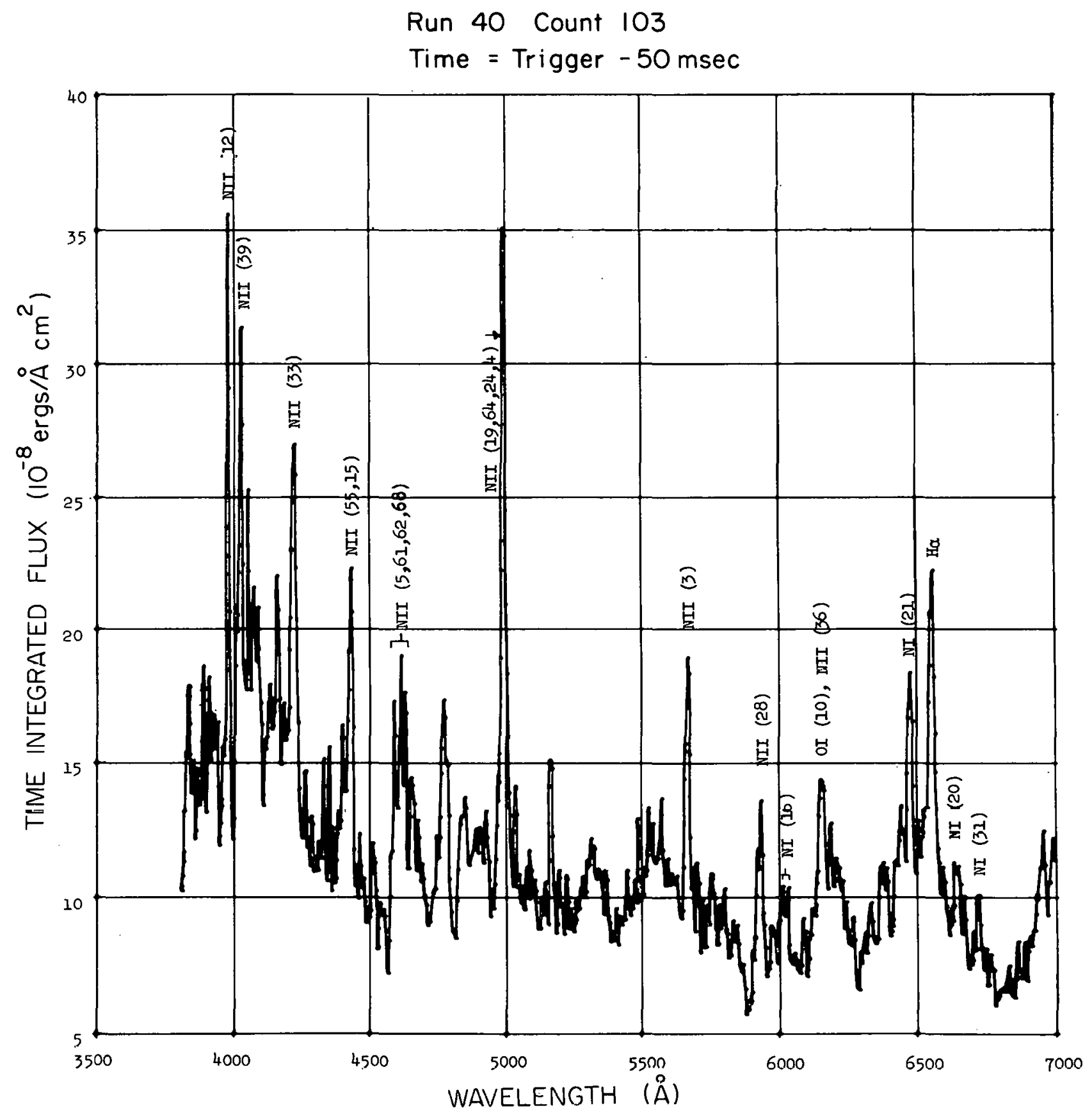

Fig. 10. Spectrum (taken at twilight) of first return stroke. Electrical enerEy deposited is unknown. Rain transmission $=3.6 \times 10^{-2}$. Visible energy radiated $=7.7 \times 10^{2}$, foule/meter, corrected for rainfall transmission. Range $=7 \mathrm{~km}$. 


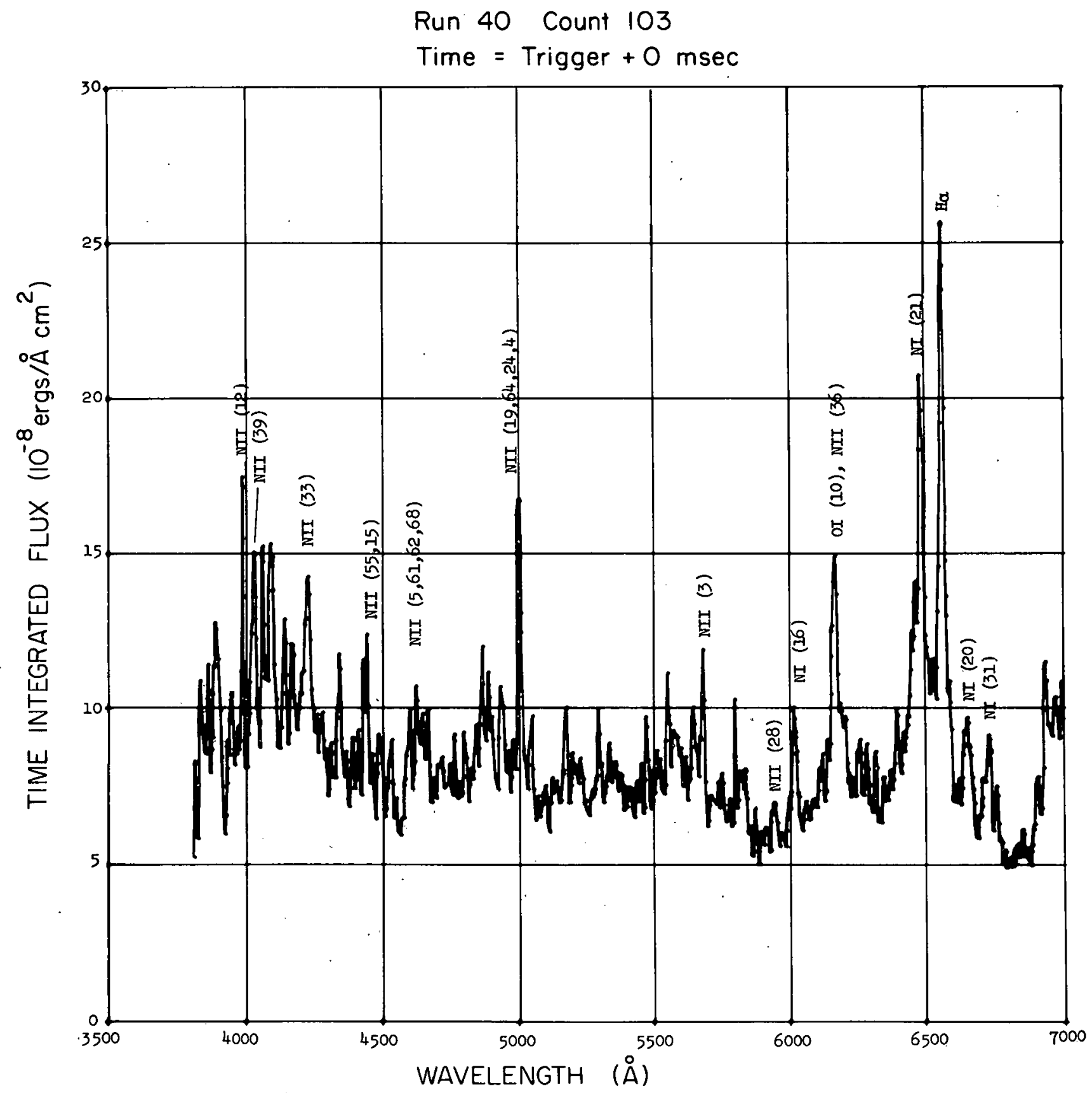

Fig. 11. Spectrum (taken at twilight) of subsequent return stroke. Electrical energy deposited is unknown. Rain transmission $=3.6 \times 10^{-2}$. V1sible energy radiated $=5.6 \times 10^{2}$ joule/meter, corrected for rainfall transmission. Range $=7 \mathrm{~km}$. 
Run 40 Count 103

Time $=$ Trigger $+31 \mathrm{msec}$

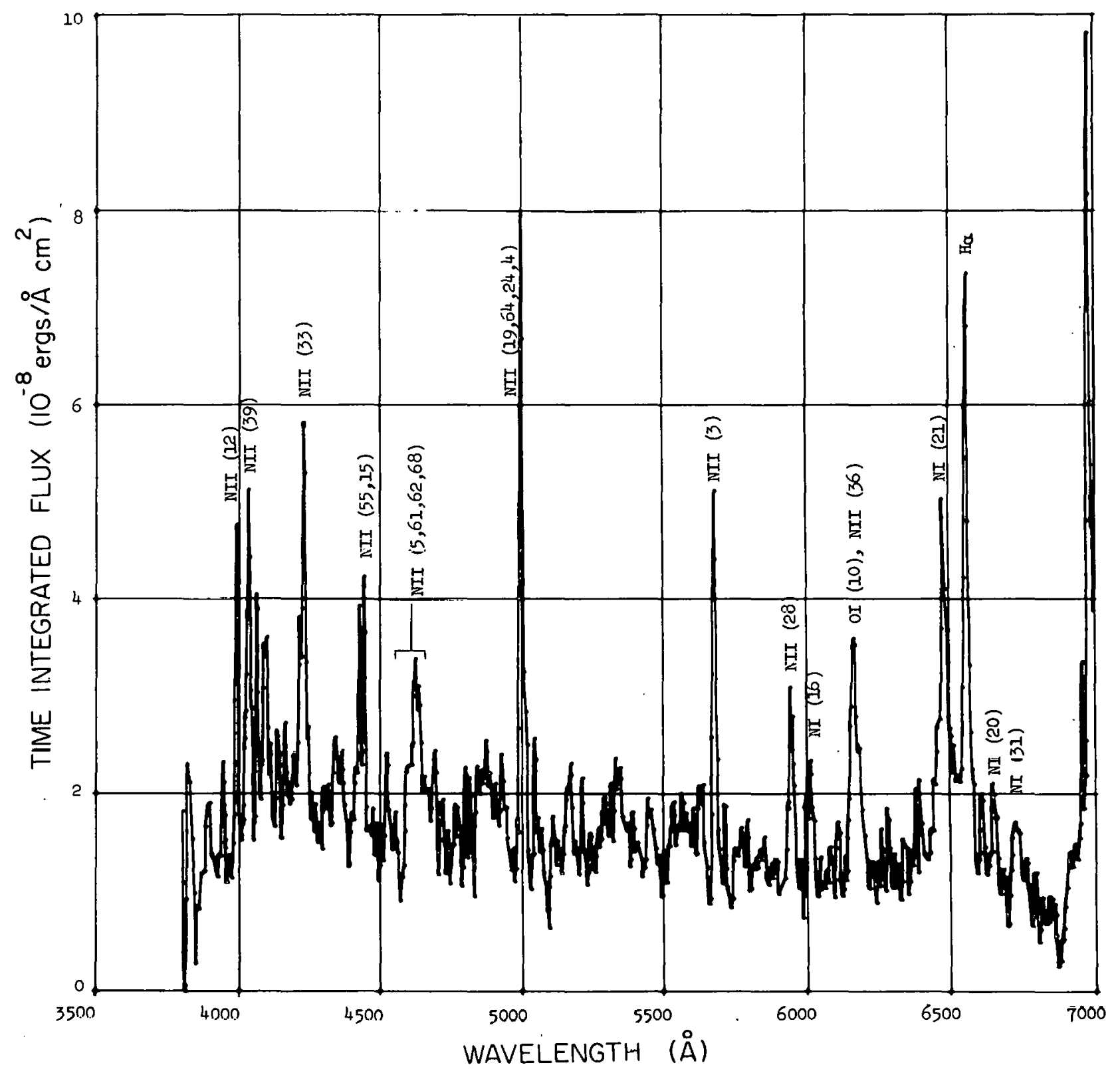

Fig. 12. Spectrum (taken at twilight) of subsequent return stroke. Electrical energy deposited is unknom. Rain transmission $=3.6 \times 10^{-2}$. Visible energy radiated $=4.2 \times 10^{1}$ joule $/$ meter, corrected for rainfall transmission. Range $=7 \mathrm{~km}$. 


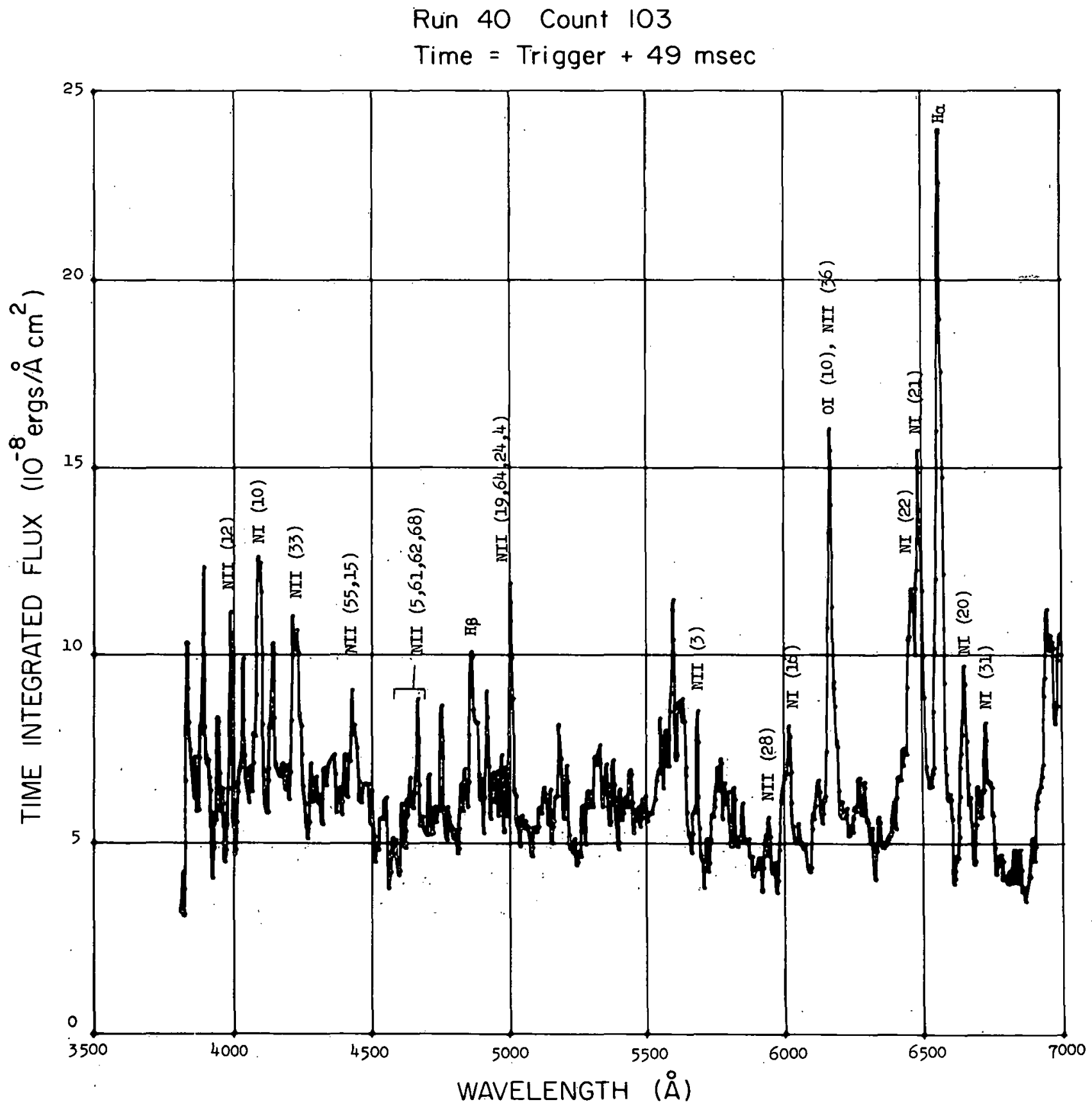

Fig. 13. Spectrum (taken at twilight) of subsequent return stroke. Electrical energy deposited $=4.0 \times 10^{4}$ joule/meter. Rain transmission $=3.6 \times 10^{-2}$. Visible energy radiated $=4.2 \times 10^{2}$ joule $/ \mathrm{meter}$, corrected for rainfall transmission. Range $=7 \mathrm{~km}$. 
Run 40 Count 103

Time = Trigger $+191 \mathrm{msec}$

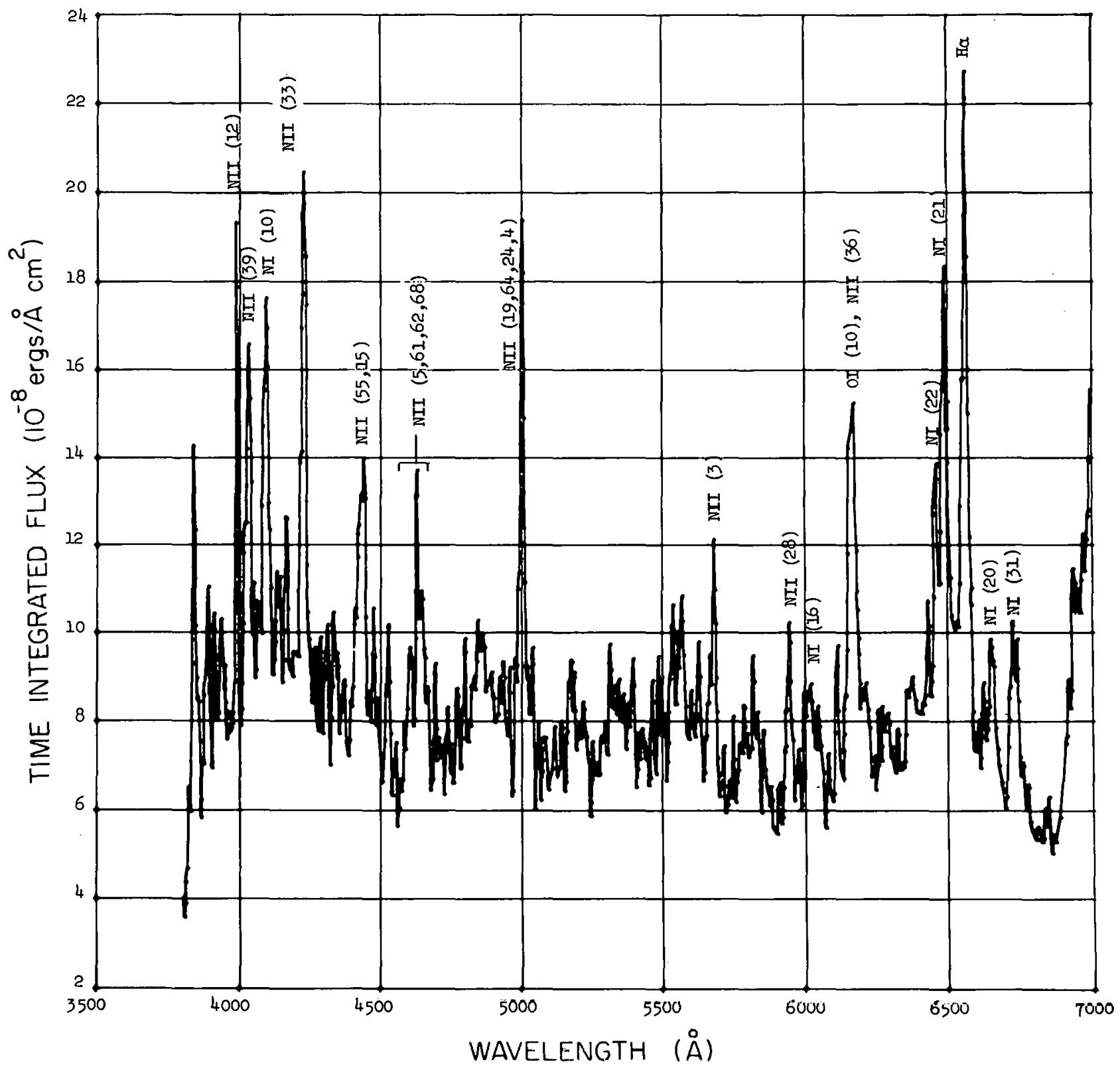

Fig. 14. Spectrum (taken at twilight) of subsequent return stroke. Electrical energy deposited $=9.0 \times 10^{4}$ joule/meter. Rain transmission $=3.6 \times 10^{-2}$. Visible energy radiated $=5.7 \times 10^{2}$ joule $/$ meter, corrected for rainfall transmission. Range $=7 \mathrm{~km}$. 


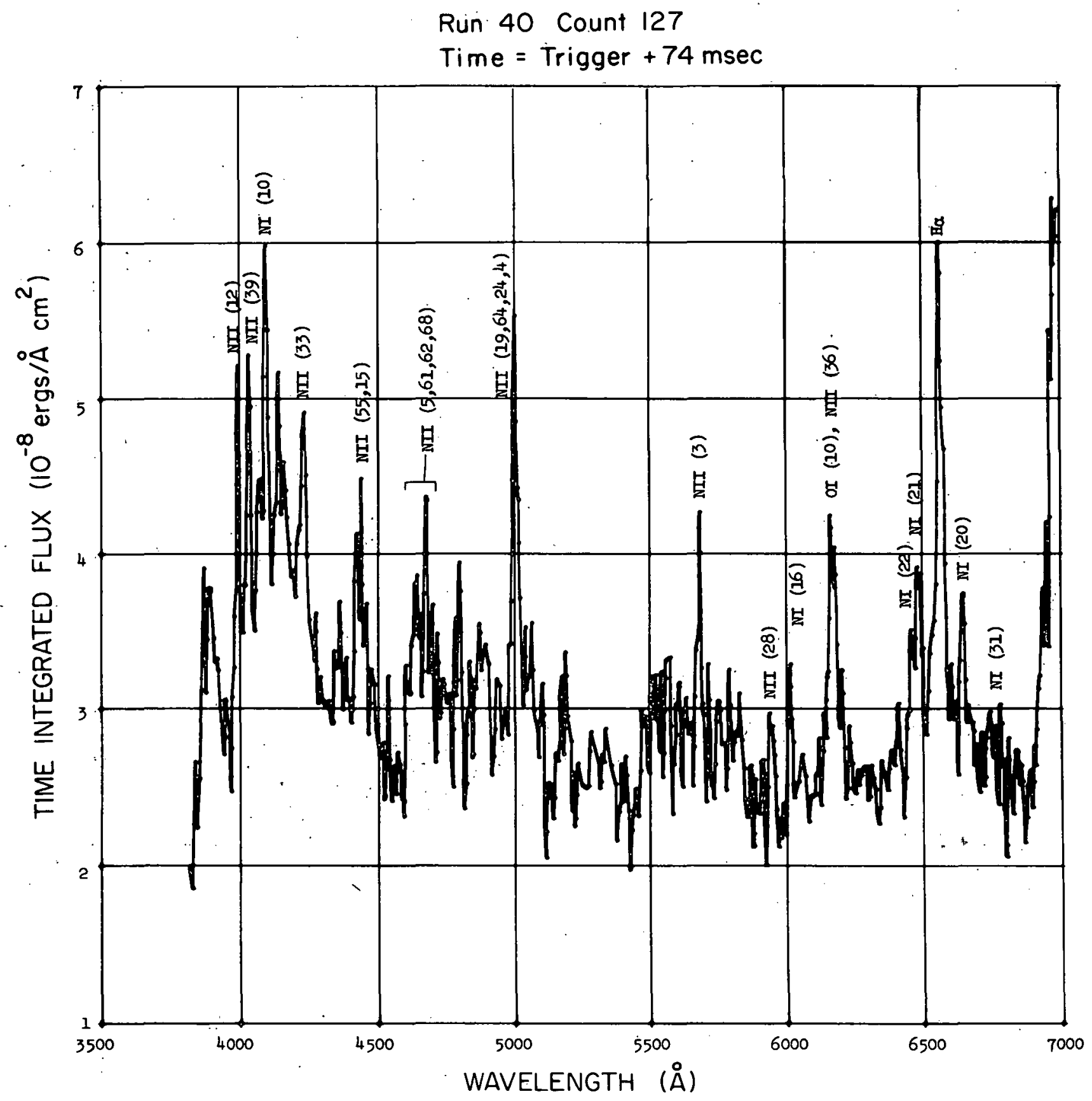

Fig. 15. Spectrum (taken at twilight) of first return stroke. Electrical energy deposited $=3.2 \times 10^{4}$ joule/meter. Rain transinission $=3.3 \times 10^{-2}$. Visible energy radiated $=2.3 \times 10^{2}$ joule $/ \mathrm{meter}$, corrected for rainfall transmission. Range $=7.2 \mathrm{~km}$. 


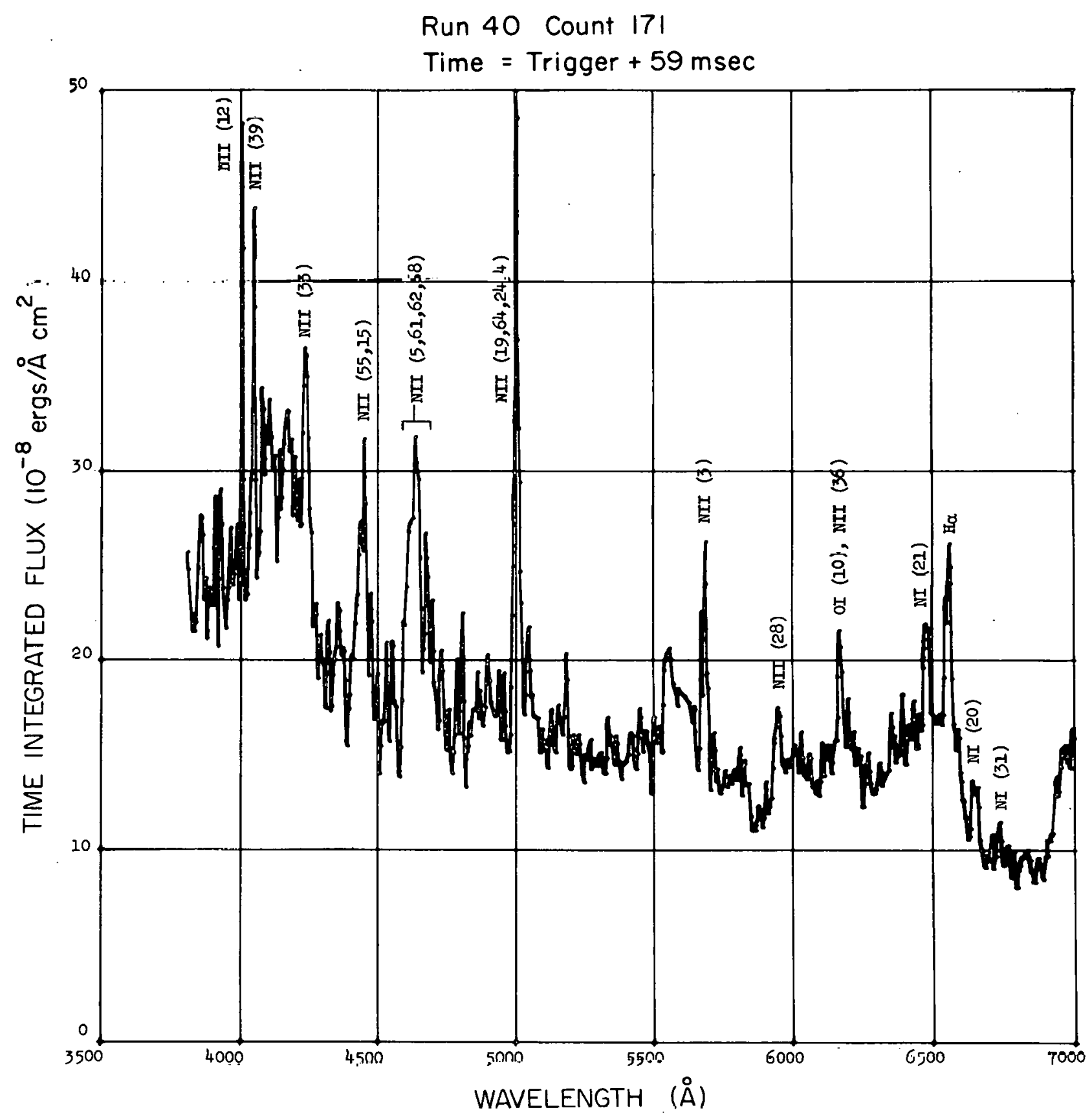

F1g. 16. Spectrum (taken at twilight) of first return stroke. Electrical energy deposited $=2.1 \times 10^{4}$ joule/meter. Rain transmission $=1.1 \times 10^{-1}$. Visible energy radiated $=2.3 \times 10^{2}$ joule/meter, corrected for rain transmission. Range $=4.0 \mathrm{~km}$. 


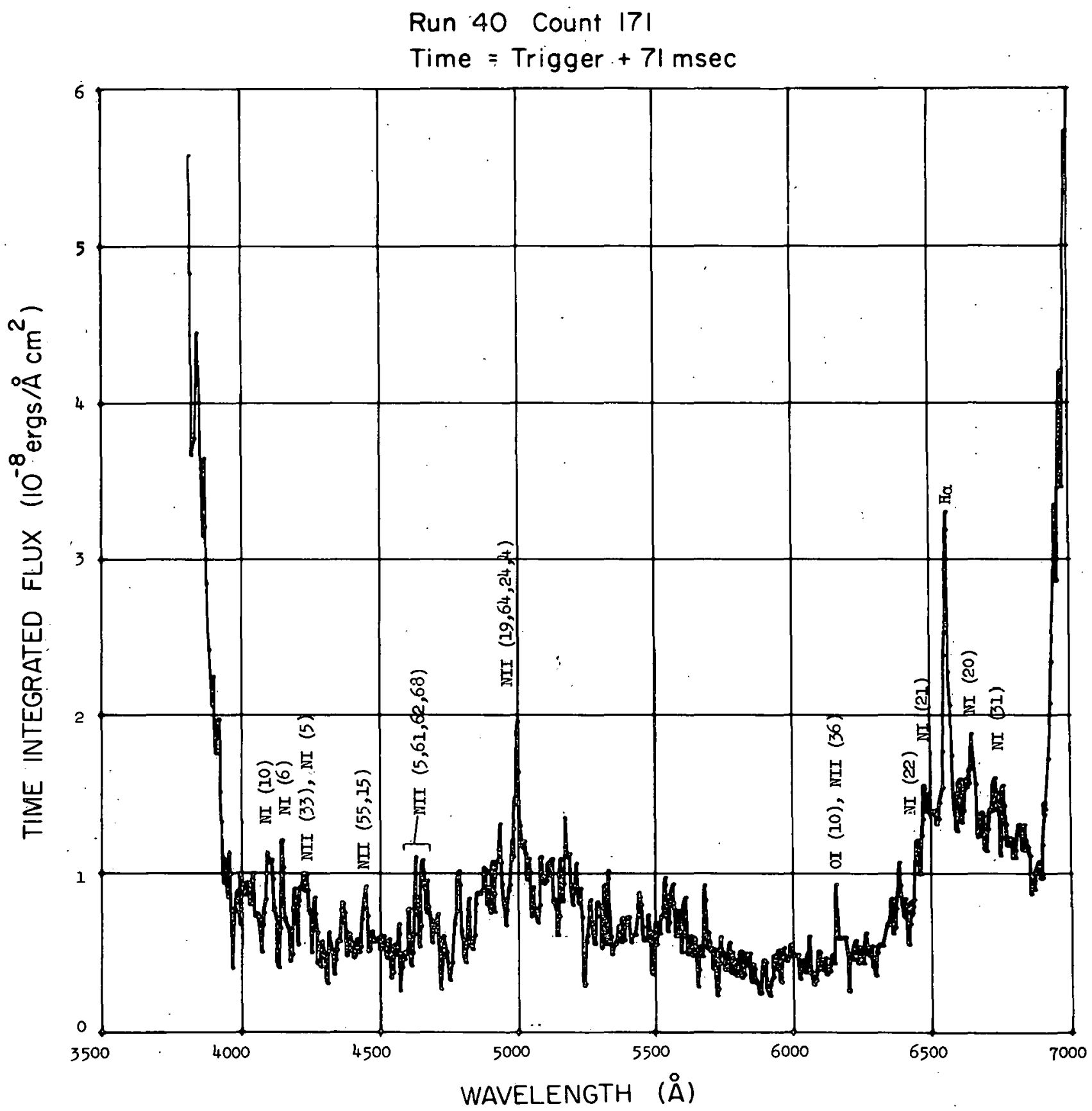

F1g. 17. Spectrum (taken at twilight) of subsequent return stroke which results in a continuing luminosity. Electrical energy deposited is unknown. Rain transmission $=1.1 \times 10^{-1}$. Visible energy radiated $=9.8$ joule $/$ meter, corrected for rain transmission. Range $=4.0 \mathrm{~km}$. 


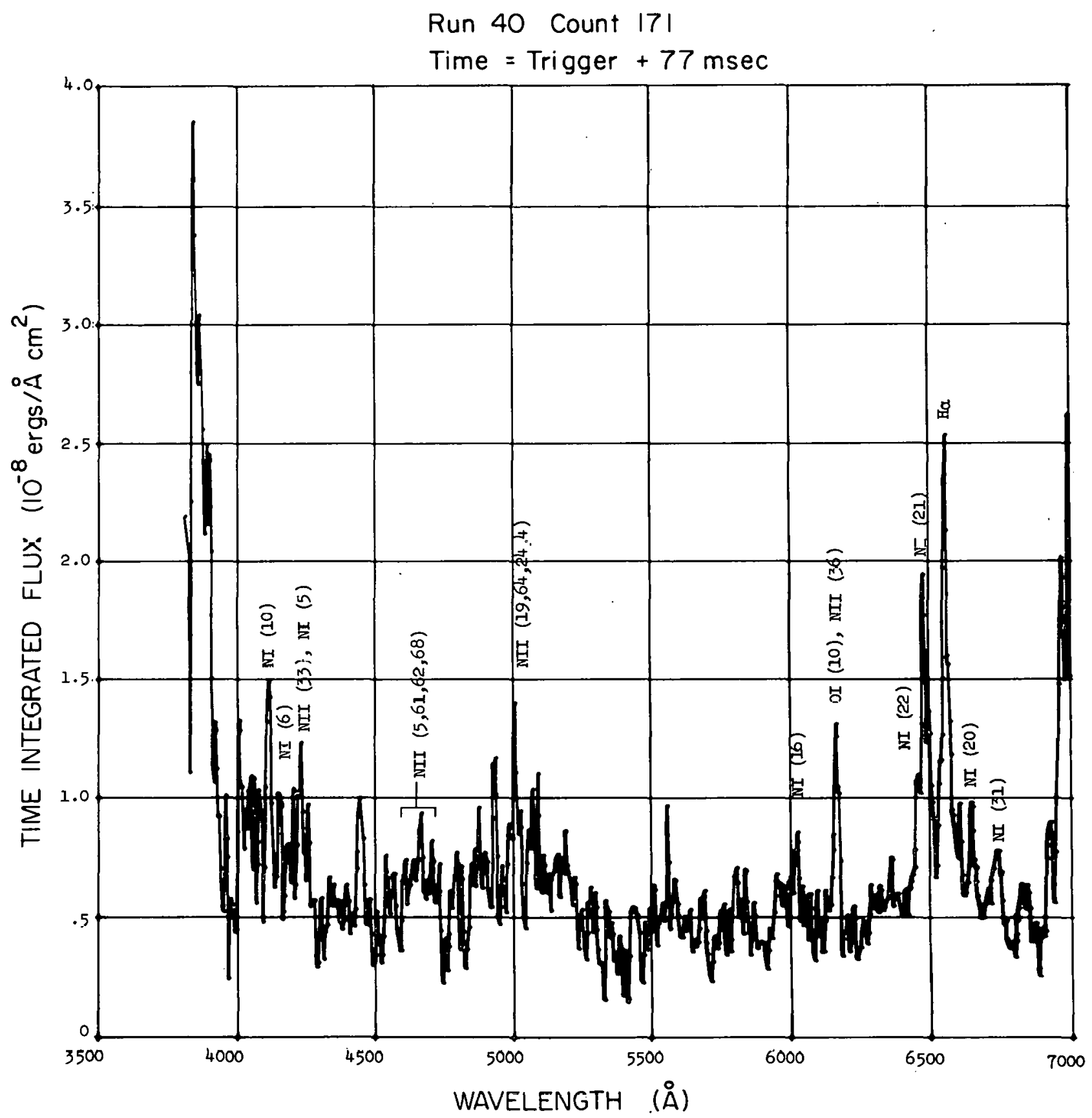

Fig. 18. Spectrum (taken at twilight) of continuing luminosity. Electrical energy deposited is unknown. Rain transmission $=1.1 \times 10^{-1}$. Visible energy radiated $=7.9$ joule/meter, corrected for rain transmission. Range $=4.0 \mathrm{~km}$. 


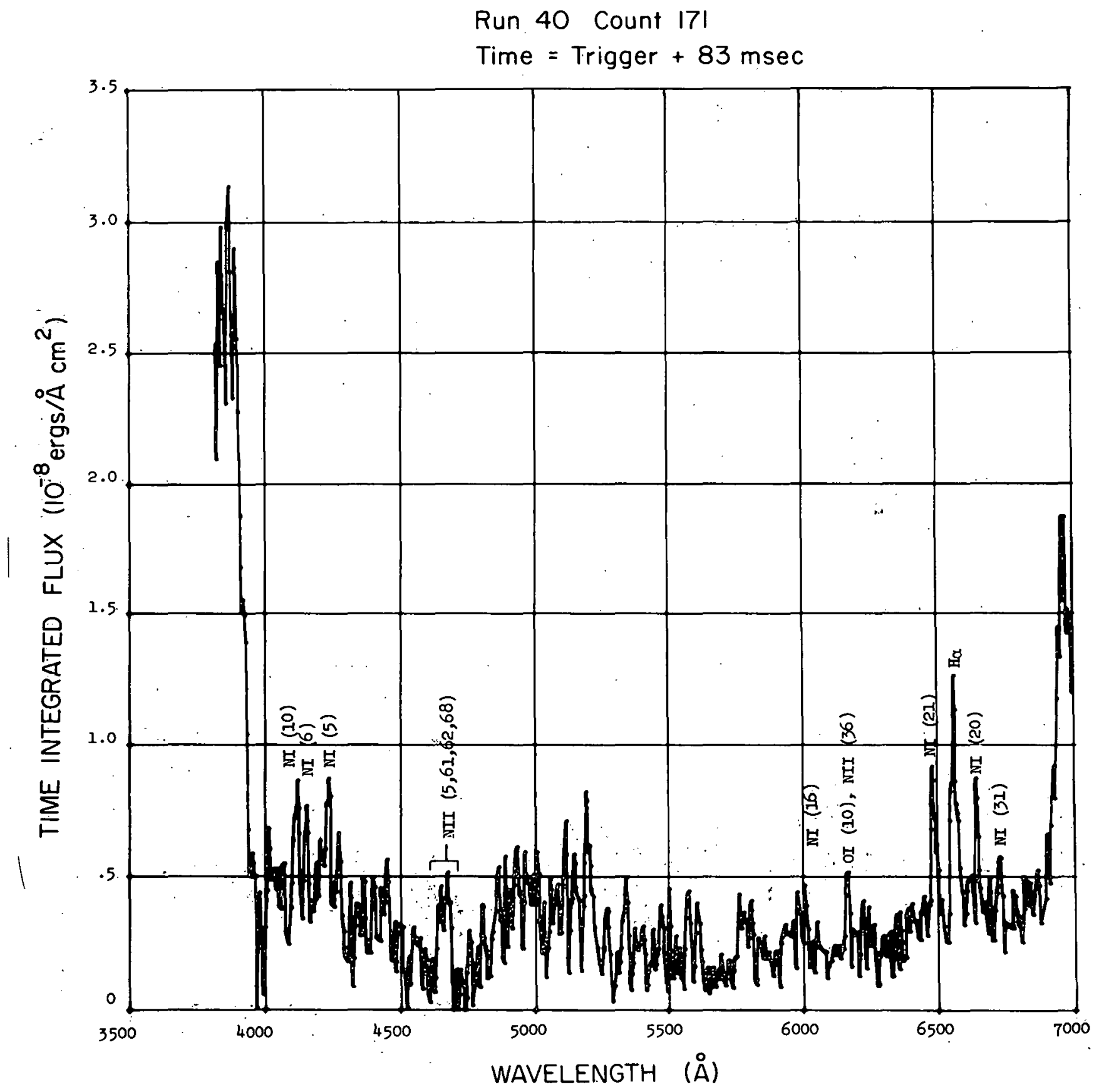

Fig. 19. Spectrum (taken at twilight) of a continuing luminosity. Electrical energy deposited is unknown. Rain transmission $=1.1 \times 10^{-1}$. Visible energy radiated $=4.3$ joule $/$ meter, corrected for rain transmission. Range $=4.0 \mathrm{~km}$. 


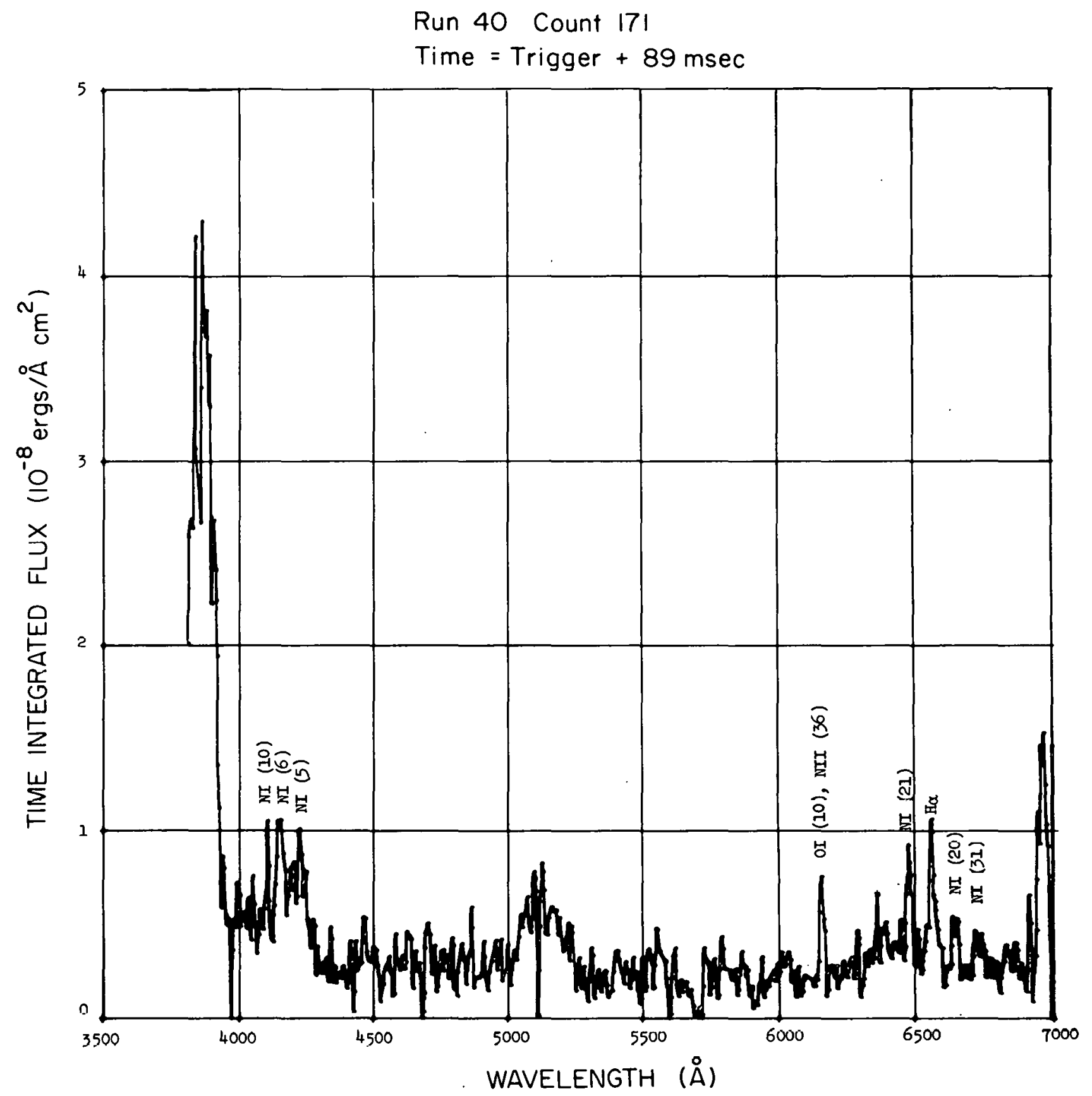

F1g. 20. Spectrum (taken at twilight) of a continuing luminosity. Electrical energy deposition is unknown. Rain transmission $=1.1 \times 10^{-1}$. Vistble energy radiated $=4.5$ joule/meter, corrected for rain transmission. Range $=4.0 \mathrm{~km}$. 


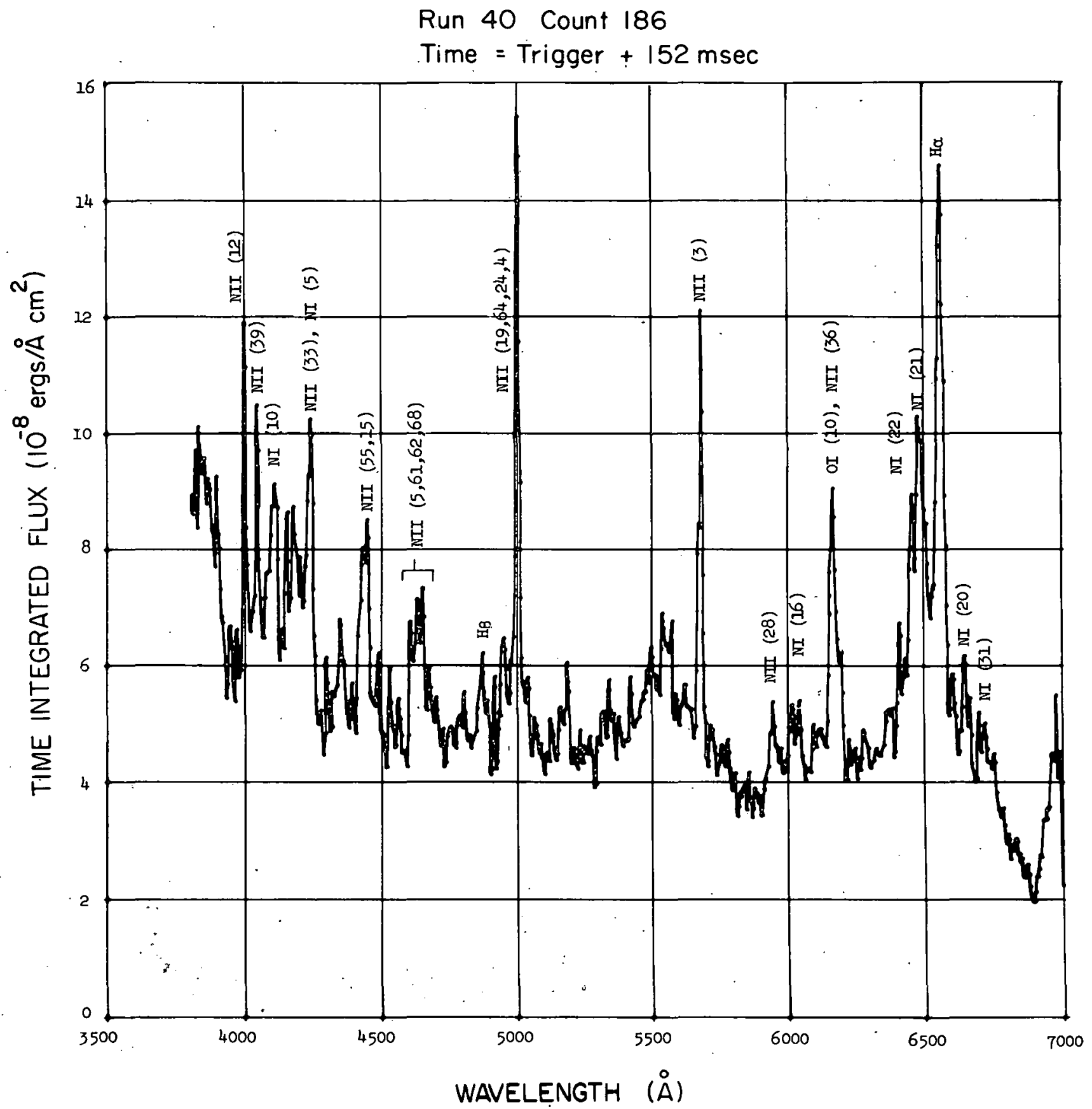

Fig. 21. Spectrum (taken at tw1light) of first return stroke. Electrical energy deposited = $2.2 \times 10^{4}$ joule/meter. Rain transmission $=1.5 \times 10^{-1}$. Visible energy radiated $=5.9 \times 10^{1}$ joule/meter, corrected for rain transmission. Range $=4.6 \mathrm{~km}$. 


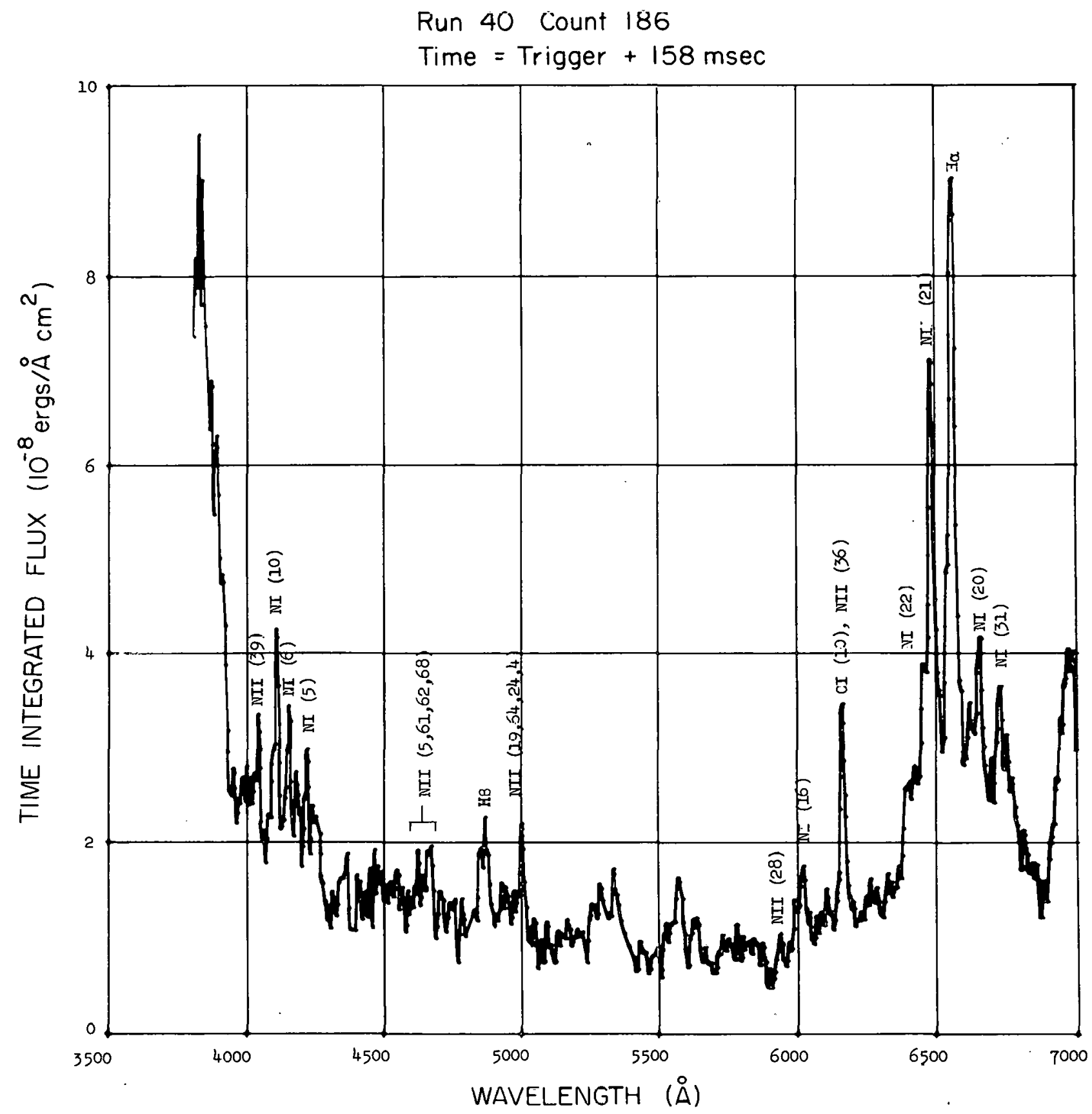

F1g. 22. Spectrum (taken at night) of continuing luminosity. 'Electrical energy deposition is uniknown. Rain transmission $=1.5 \times 10^{-1}$. Visible energy radiated $=1.9 \times 10^{2}$ joule/meter, corrected for rain transmission. Range $=4.6 \mathrm{~km}$. 


\section{Run 44 Count 195 Height $=\mathrm{H}+$ O meters \\ Time $=$ Trigger $+75 \mathrm{msec}$}

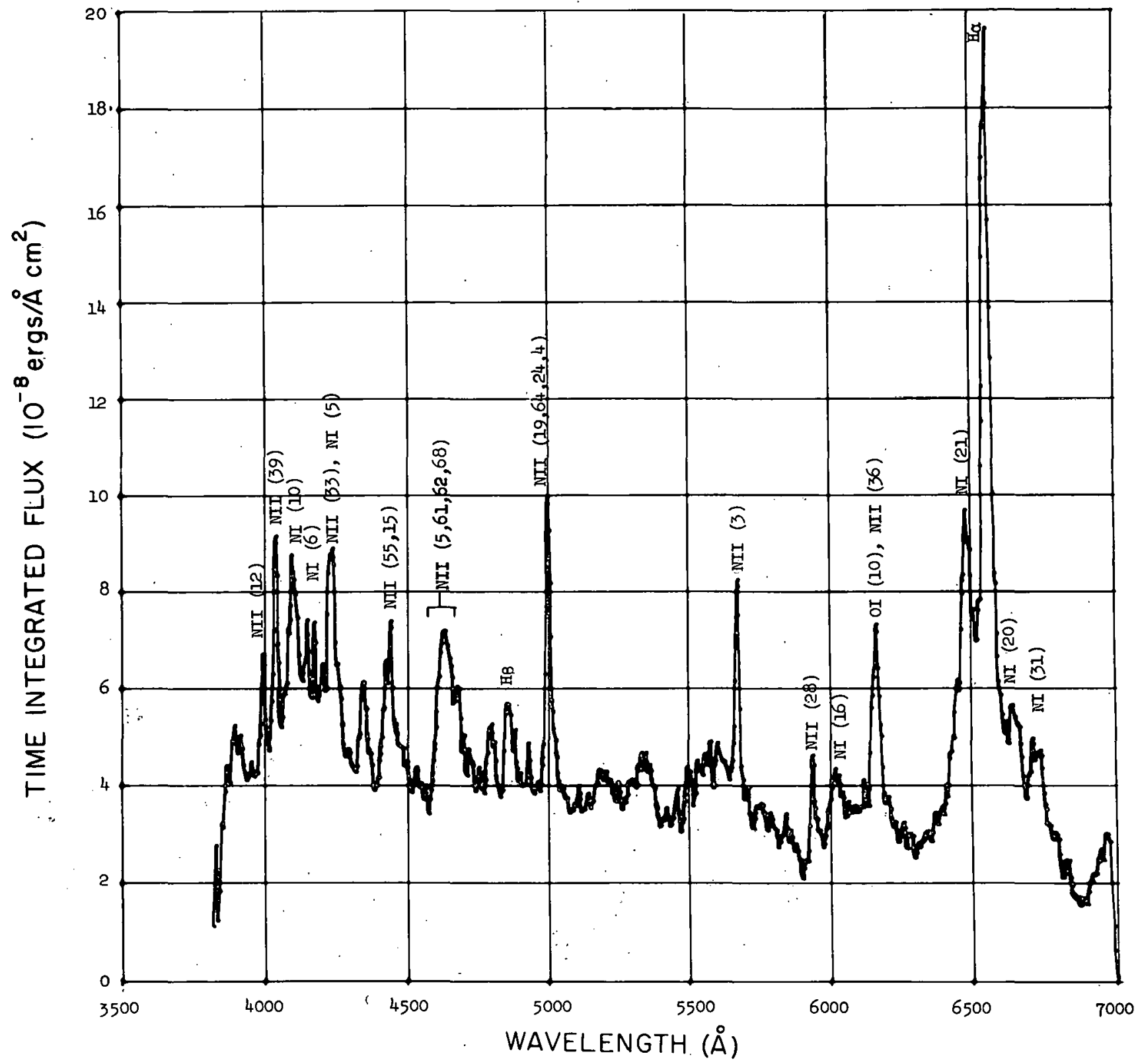

Fig. 23. Spectrum (taken at night) of probable first return stroke. Electrical energy deposited and rain transmission are unknown. Spectrum corresponds to an element of the channel at fiducial altitude H. Visible energy radiated $=1.9 \times 10^{1}$ joule/meter, not corrected for rain transmission. Range $=12 \mathrm{~km}$. On the basis of distribution as a function of range of absolute irradiances, as measured by collimated photometers, the rain extinction coefficient is estimated to be $0.15 \mathrm{~km}^{-1}$. Thus, estimated rain transmission for this count is $\sim 1.7 \times 10^{-1}$. 


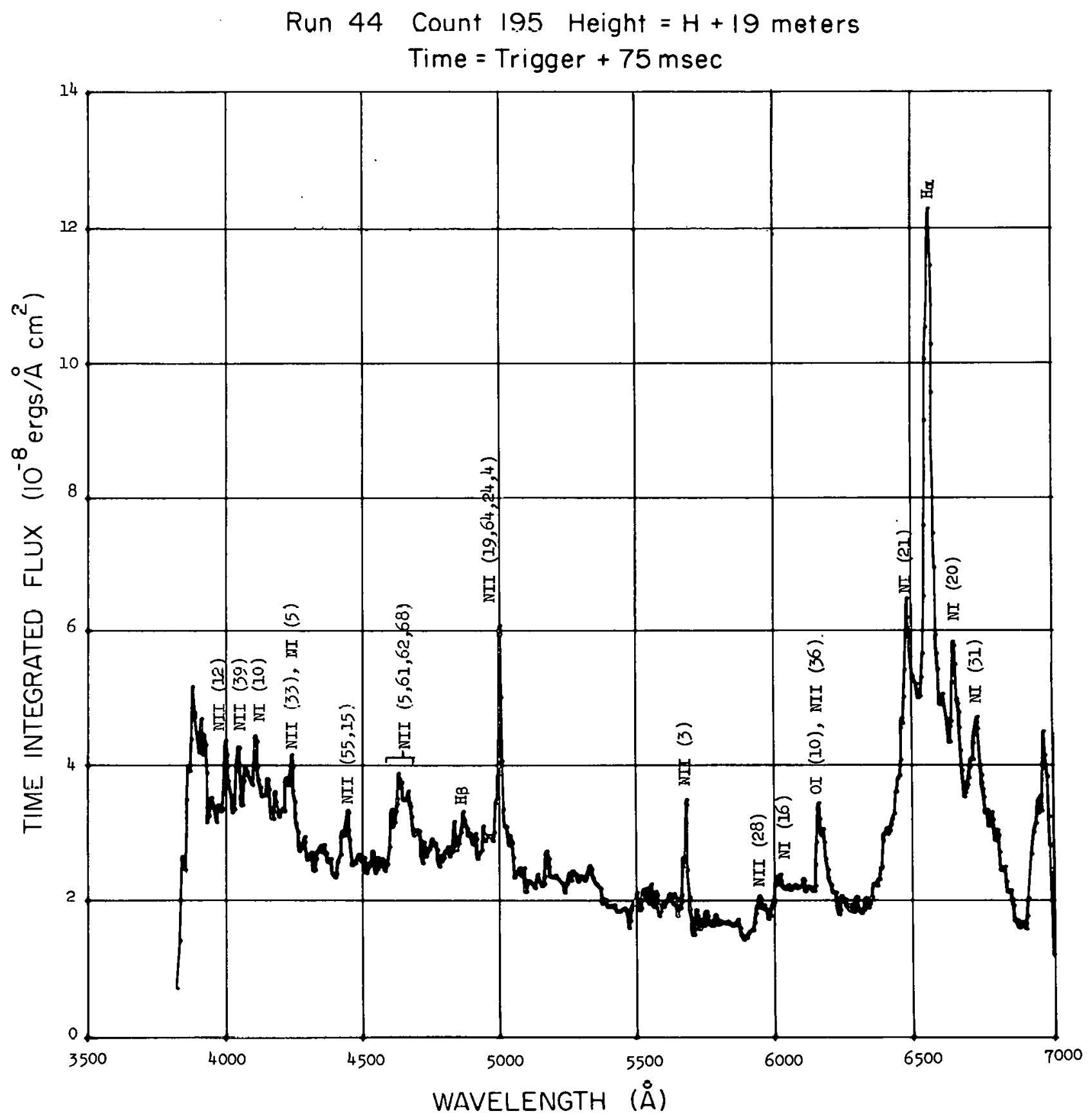

F1g. 24. Spectrun (taken at night) of probable first return stroke. Electrical energy deposited and rain transmission are unknown. Spectrum corresponds to an element of the channel at altitude $H+19$ meters. Visible energy radiated $=1.2 \times 10^{1}$ joule/meter, not corrected for rain transmission. Range $=12 \mathrm{~km}$. Estimated rain transmission $\sim 1.7 \times 10^{-1}$ (refer to Fig. 23 caption). 


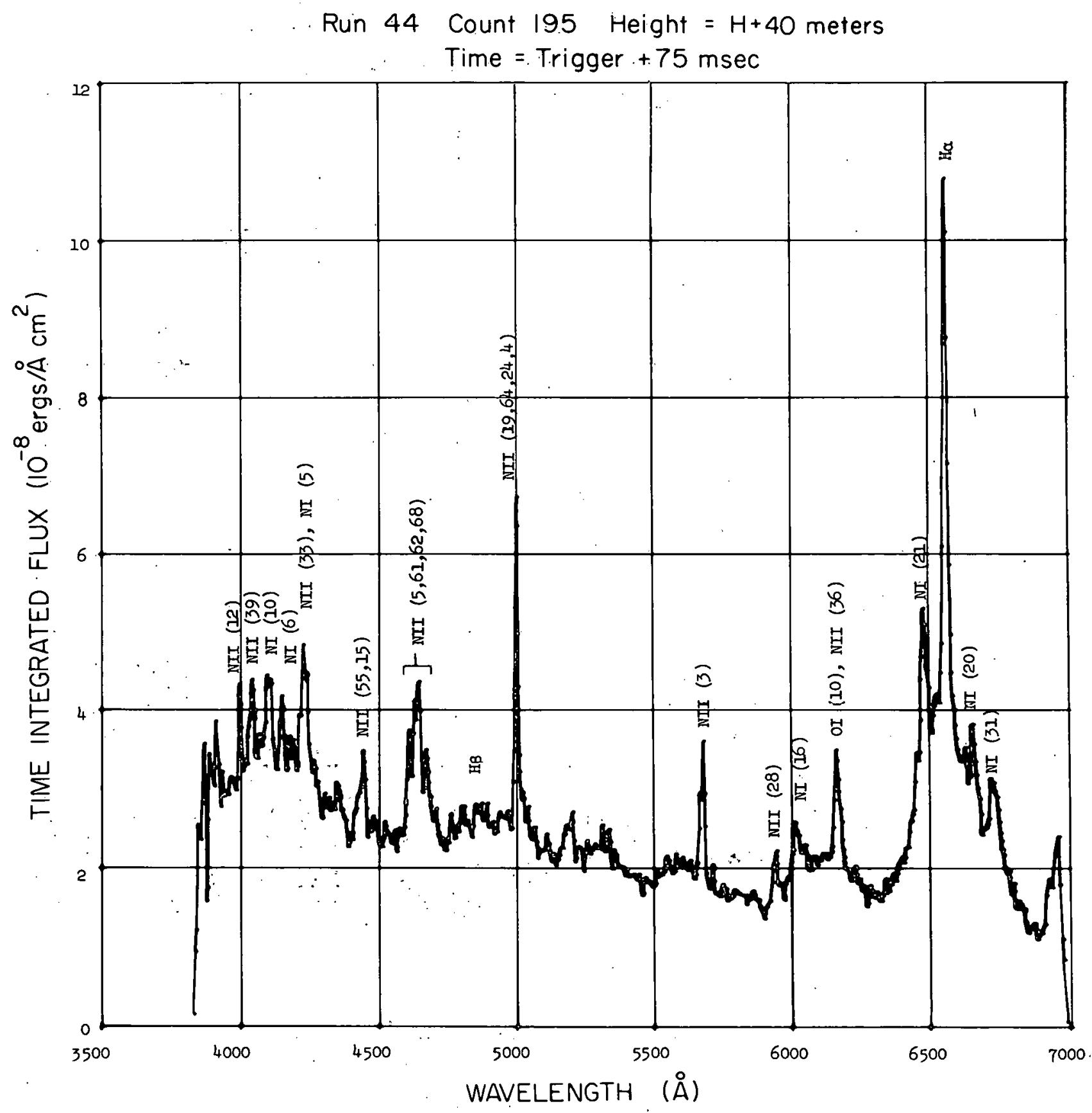

F1g. 25. Spectrum (taken at night) of probable first return stroke. Electrical energy deposited and rain transmission are unknown. Spectrum corresponds to an element of the channel at altitude $\mathrm{H}+40$ meters. Visible energy radiated $=1.1 \times 10^{1}$ joule/meter, not corrected for. rain transmission. Range $=12 \mathrm{~km}$. Estimated rain transmission is $\sim 1.7 \times 10^{-1}$ (refer to Fig. 23 caption). 
1. First returin strokes - The strong line features are attributable to the specles $\mathrm{NI}$, NII, OI, $H I$, and there are no molecular bandheads. If the spectrum were viewed by a 20- to 30- $\AA$-bandwidth detector, the strongest feature, on the average, would be the blend of four NII multiplets at $5000 \AA$. (A feature such as NII (12) at $3995 \AA$ A mave a higher peak, as seen by the spectrograph, but it is mach narrower.) There is also a high density of weaker multiplete between 4000 and $4250 \AA$, and an $H a$ reature appears which, an the average, is moderately strong. Uoling tho patio of NII to FI radiation ao a measure, the degree of lonization is higher in first return strokes than in elther subsequent return strokes or continuing luminosities. The best est1mate of a strialght-line f'lt to the continuum shors that the ratio of the continuum at $3900 \AA$ to that at $6900 \AA$ is $\sim 2$.

\section{Subsequent return strokes - Strong line} features are attributable to the specles NI, NII, OI, and HI, and there are no molecular bandheads. If the spectrum is viewed by a 20 - to $30-\AA$ bandwidth detector, the strongest feature 1s, in every case, $\mathrm{Ha}$ at $6563 \AA$. The next strongest is NII at $5000 \AA$, but it is not, on the average, much stronger than a few of the multiplets which make up a blend of features between 4000 and $4250 \AA$. The degree of Ionization is lower than in first return strokes and higher than in continuing luminosities. The best estimate of a straight-line lit to the continuum shows that the ratio of the continuum at $3900 \AA$ to that at $6900 \AA$ is $~ 1.6$.

3. Continuing luminosities - The jor line features are attributable to NI, OI, and HI, with very weak NII. The strongest line feature in every case is Ha. The degree of lonization is lower than for return strokes. The best estimate of a straightline fit to the continuum gives a ratio of continum at $3900 \AA$ to that at $6900 \AA$ of $\sim 1$. There is a very much stronger, very broad blend of features between 3800 and $3900 \AA$. Upon reehecking arlg1ral callbrations, reducing additionsl calibration data, and checking the magnitude of possible errors incurred in subtraction of daylight background, I must conclude that this blend of features is depinitely real. In addition, the spectro of continuing luminosities are in qualitative agreement with those of
Salanave. In Salanave's spectra, IInes and bands are smeared in wavelength due to his method of recording, but he was able to conclude that "the continuing luminosity seems definitely strongest in that part of the spectrum favored by the $\mathrm{CN}$ and $\mathrm{N}_{2}^{+}$ bands, and Ha."I The spectra presented here seem to show that continuing luminosities are not a major source of $\mathrm{N}_{2}^{+}$iN seen by lang exposure sllt spectrographs.

As mentioned above, the callbrations are being reworked using additional data which should yield the best posstble reduction. Preliminary results Indicate an overall change in the spectra, such that the flux will be 20 to $30 \%$ higher in the blue, 5 to $15 \%$ higher in the green, and 0 to $10 \%$ lower in the red.

\section{F. Discrimination}

While the lightning spectra are not a large statistical sample, they do give complete wavelength coverage between 3900 and $6900 \AA$, and are therefore useful in determining whether or not there may be other or better discrimination channels than either $4150^{10}$ or $6563 \AA$.

The merit of a discrimination channel must be based on the following parameters: (1) its spectral width and its average signal relative to that of the $3914-\AA$ detection channel, (2) the sensitivity of the photodetector at the wavelength of the discrimination channel relative to that at $3914 \dot{A}$, (3) atmospheric transmission at the wavelengths for detection and discrimination, and (4) the fleld of view and related considerations of the path by wich light propagates into the detector, which can cause changes in the relative spectrum detected.

A quantitative discussion of these parameters for a discrimination channel will be presented in Volume 4. However, it is worth pointing out that a 20- $\AA$-wide discrimination channel centered on a blend of NII multiplets near $5000 \AA$ may be as good or better a discriminant, under a varlety of storm and background light conditions, than one at elther 4150 or $6563 \AA$.

It seems worthwhile to Investigate the possibility of using a narrow band, $5000-\AA$ channel. Toward this end the large statistical sample of 
Table II. Field Change Calculations

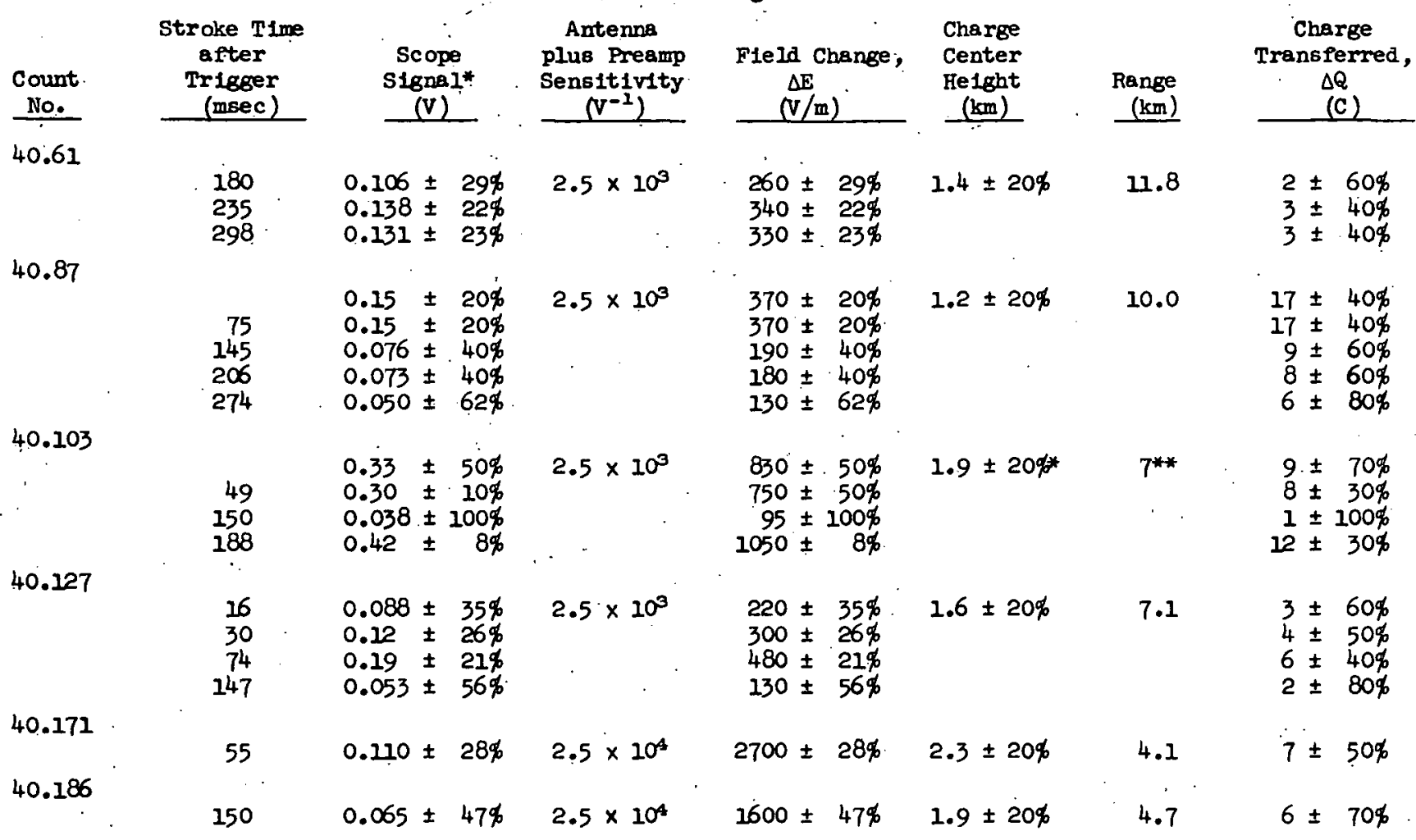

* The error corresponds to the halfwidth of the oscilloscope beam except for those signals occurring at $t_{0}$. If the signal occurred at $t_{0}$, the fleld strength before the stroke was unknown and the field change was estimated by comparing the Ha signal with other strokes of the same flash. The error in this case is the estimated error.

* No ranging pictures were avallable. After a check of avallable ranging data for other, counts, a range of $7 \mathrm{~km}$ was assumed. A plot of channel length vs range from ranging plcture data furthermore ind 1cates that the vertical component of a channel at $7 \mathrm{~km} 181.6 \mathrm{~km}$. Iater data on thunder Indicates a range of $\sim 6 \mathrm{~km}$.

broadband $(\sim 200-\AA)$ data for a chaninel whlch includes $5000 \AA$, taken by EG\&G-operated all-sky photometers, 11 and the slit spectra obtalned during the summer of $1966 \mathrm{will}$ be used in the discrimination. and false alarm analysis of volume 4.

\section{CALCULATION FROM ELECTRIC FIELD ANIENNA DATA}

OF THE CHARGE TRANSFHRRED TO GROND BY IICHTNING

During the 1965 ARPA-ABC joint lightning study, IASI operated three electric fleld antennas. ${ }^{7}$. Two of these antennas gave data on the change in the vertical component of the quasidc electric fleld caused by a lightning flash. Knowing the range and the channel length from ranging pictures and having measured the electric fleld change, it was then pos- sible, on the basis of a dipole model, to calculate the charge transferred to the ground. The dipole is formed by a negative charge center near the bottom of the cloud and 1ț Image charge in the ground. It 1s the destruction of this dipole during a lightning stroke which produces the measured fleld change. The charge transferred, $\Delta Q$, is then given by the following expression which is equivalent to that Given by Malan. 12

$$
\begin{aligned}
\Delta Q & =2 \pi \epsilon_{0}\left[\frac{h^{2}+R^{2}}{\sin \arctan \left(\frac{h}{R}\right)}\right] \Delta E \\
& =5.55 \times 10^{-5} \times \frac{h^{2}+R^{2}}{\sin \arctan \left(\frac{h}{R}\right)} \times \Delta E,
\end{aligned}
$$

where $\mathrm{h}$ 18 the helght of the charge center above 
ground in kiloweters, $R$ is the distance from the strake to the antenno in kilometers, $\Delta E$ is the vertical fleld change in volts per meter, and $\Delta Q$ is in coulambs. The value of $h$ was obtained by measuring the vertical component of the length of the visible channel between ground and the cloud and assuming that the charge center was $20 \%$ higher, Inside the cloud.

The "slow antenna" 13 was bullt by Marx Brook of the New Mexico Institute of Mining and Technology, and lent to IASL for the lightning study. Its signals were recarded both on an osc1lloscope, giving fleld changes for the various strokes in a flash, and on paper chart, giving the total field change for a flash. The A2 anteana was a vire suspended aboit a metar ahnue the for ound whioh wao lept at the same potential as the surrounding air by means of a radioactive source hung near its center, as described by Schonland.14 The signel from this antenna was recorded on paper chart only and gave total fleld change for a flash.

Table II contains the results of the calculation for fleld changes measured from the "slow antenna" scope records.

The total field changes and total charge transferred in a flash are shown in Table III.

Table III. Total Field Change and Charge Transferred Durlng Flash

A2 Antenna Chart Data

Count $\Delta E \quad \Delta Q$

No. $(\mathrm{V} / \mathrm{m})$ (C)

$40.61 \quad 1400 \quad 13$

$40.87 \quad 1700 \quad 80$

$40.103 \quad 4500 \quad 50$

$40.127 \quad 3600 \quad 47$

$40.171 \quad 6000 \quad 16$

40.186

1700

7

36

\begin{tabular}{|c|c|c|c|}
\hline \multicolumn{2}{|c|}{$\begin{array}{l}\text { Slow Antenna } \\
\text { Chart Data }\end{array}$} & \multicolumn{2}{|c|}{$\begin{array}{l}\text { Slow Antenna } \\
\text { Scoge Data }\end{array}$} \\
\hline $\begin{array}{l}\Delta E \\
(v / m)\end{array}$ & $\begin{array}{l}\Delta Q \\
\text { (C) }\end{array}$ & $\begin{array}{c}\Delta E \\
(\mathrm{~V} / \mathrm{m})\end{array}$ & $\begin{array}{r}\Delta Q \\
(\mathrm{C})\end{array}$ \\
\hline 14.00 & 13 & 930 & \\
\hline 1420 & 67 & 1120 & , \\
\hline 3300 & 36 & 2730 & 3 \\
\hline 2500 & 33 & 2130 & 1 \\
\hline 1850 & 5 & 2700 & \\
\hline 3840 & 15 & 1600 & 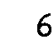 \\
\hline & 28 & & 2 \\
\hline
\end{tabular}

Average

On the basis of the estimated errors from Table II, and the scatter in the results in Table III, the uncertainty in the calculation of the charge transferred may be about a factor of two.
The average charge transferred per stroke for 18 strokes given in Table II is 7 coulombs/stroke. Th1s agrees with the value of 5 coulombs quoted by Malan 12 as the average charge dissipated to ground by the firat stroke of a lightning flash. Malan also gives 20 coulambs as the average charge transferred to ground per flash, whlch is in good agreement with the 28-coulomb average for six flashes given in Table III.

The value of charge transferred in a given return stroke is used in the next section to calculate the energy deposited in the channel.

\section{EFFICIENCY OF CONVERSION OF ELECTRICAL ENERGY} INTO VISIBLE RADIATION IN A LTGHTNDNG CHANNEL

For the spectra presented in Section II D, the energy radiated in the visible wavelength interval $3900 \AA \leq \lambda \leq 6900 \AA$ per meter of vertical component of the channel has been calculated. Each plint of the time-integrated spectral irradiance (joules $/ \mathrm{cm}^{2} \AA$ ) vs wavelength at the spectrograph's entrance pupil was integrated over the wavelength range throughout which the spectrograph calibrations were known accurately. The wavelength - and time-integrated irradiance, $H$, thus calculated was used with the range, $R$, and channel helght, $h$, measured by photographic triangulation, ${ }^{\top}$ to calculate the energy per meter radiated by the channel:

$$
w=4 \pi R^{2} \mathrm{H} \mathrm{h}^{-1} \text { joules/meter. }
$$

Table IV contains the results of the energy calculations. Corrections have been made for atmospheric selective transmission. No correction for extinction by rain between source and detector has been included. Using the results of charge-transfer calculations made for these strokes, and range and helght infarmation from the triangulation photographs, the energy deposited per meter has been calculated.

The potential, $v$, of an elemental charge, $q$, relative to a conducting plane at a distance, $h$, is

$$
v=\frac{1}{4 \pi \varepsilon_{0}} \frac{q}{2 h} .
$$

The energy, $W$, required to assemble a charge, $Q$, at 
Table IV. Calculation of V181blo Energy

\begin{tabular}{|c|c|c|c|c|c|}
\hline $\begin{array}{c}\text { Count } \\
\text { No. }\end{array}$ & $\begin{array}{l}\text { Strake } \\
\text { T1me } \\
\text { orter } \\
\text { Trieser } \\
\text { (msec) } \\
\end{array}$ & $\begin{array}{r}\text { Range } \\
\text { (km) }\end{array}$ & $\begin{array}{l}\text { Length of } \\
\text { Channel } \\
\text { Element } \\
\text { (meters) } \\
\end{array}$ & $\begin{array}{c}\text { Altitude } \\
\text { of } \\
\text { Channel } \\
\text { Element } \\
\text { (meters) }\end{array}$ & $\begin{array}{r}\text { VIstble } \\
\text { Enersy } \\
\text { Joules } \\
\text { meter }\end{array}$ \\
\hline 40.87 & 87 & 10.0 & 11 & & 27.4 \\
\hline 40.103 & $\begin{array}{r}-50 \\
0 \\
31 \\
49 \\
191\end{array}$ & 7.0 & 7.8 & & $\begin{array}{l}27.6 \\
20.3 \\
1.53 \\
15.2 \\
20.6\end{array}$ \\
\hline 40.127 & 74 & 7.2 & 8.0 & & 7.5 \\
\hline 40.171 & $\begin{array}{l}59 \\
71^{*} \\
77^{*} \\
83^{*} \\
89^{*}\end{array}$ & 4.0 & 4.4 & & $\begin{array}{c}24.8 \\
1.08 \\
0.87 \\
0.47 \\
0.49\end{array}$ \\
\hline 40.186 & $\begin{array}{l}152 \\
158^{*}\end{array}$ & 4.6 & 5.1 & & $\begin{array}{l}8.75 \\
2.77\end{array}$ \\
\hline 44.195 & 75 & 12.0 & 13.3 & $\begin{array}{l}H * * \\
H+19 \\
H+40\end{array}$ & $\begin{array}{l}19.0 \\
11.7 \\
10.6\end{array}$ \\
\hline
\end{tabular}

*In the case of count 40.186 , the stroke at 152 msec resulted in a time-streaked spectrum due to a continuously luminous channel; thus, while there was no "strokse" 158 msec after the trigger, this number indicates the center of the time interval over which the flux was time integrated. A similar situation exists for count 40.171 at times $71,77,83$, and $89 \mathrm{msec}$ after the trisger.

* The part of the channel imaged vithin the densitometer slit, 1.e., the vertical length of channel over which the spectrum energy was integrated.

** In the case of count 44.195 the spectrum was high enough to permit three different densitometer scans.

a distance, $h$, from the ground 18 then

$$
w=\int_{0}^{Q} v a q=\frac{1}{4 \pi \varepsilon_{0}} \int_{0}^{Q} \frac{q}{2 h} d q=\frac{1}{4 \pi \varepsilon_{0}} \frac{Q^{2}}{4 h} \text {. }
$$

Assuming that this enerey is diss1pated in a lightning chandel by the transfer of charge to ground, the enercy deposited per meter is

$w=\frac{1}{4 \pi \varepsilon_{0}} \frac{Q^{2}}{4 h^{2}}=2.25 \times 10^{9}\left[\frac{Q(\operatorname{coul})}{h(\text { meter })}\right]^{2} \frac{\text { joule }}{\text { meter }}$.

Using these values of deposited energy and measured values of visible energy radiated, the efficiency, $\epsilon$, for conversion of electrical eperby to visible radiation can be calculated. However, the values of visible energy given in Table IV mist Pirst be corrected for transmission through rain.

Transmission through rain 1s discussed in the Append1x. To determine the rain extinction coefficlent, it was first assumed that it was raining all along the path to the stroke at a rate of $10 \mathrm{~mm} / \mathrm{hour}$ wich corresponds to a typical Los Alemos rainfall. Th1s rate carresponds to an extinction coefficient of $\sim 0.86 \mathrm{~km}^{-1}$. Assuming values ranging from 0.0 through 2.0 for the extinction coefficient, 1t was possible to calculate an efficiency for seven strokes. The largest errors in the efficlencles are due to uncertainties in the rain transmission correction. These uncertainties are smllest for the closest atrokes and proportional to the rain transmission correction. Therefore, a welghted average of the efficlency is taken in which the rain transmission, $T_{r}$, is the veighting factor. The weighted average is then

$$
\bar{\epsilon}=\frac{\Sigma T_{r}}{\Sigma r_{r}} \text {. }
$$

For each value of extinction coefficient assumed, an average deviation was calculated, and the plot of mean deviation vs extinction coefficient is show in Fig. 26. It is seen that there is a minimum mean deviation for an extinction coefficient of 0.475 $\mathrm{km}^{-1}$. Th1s flgure was selected as the best est1mate of the rain extinction cofficient and corresponds to an average rainfall of appoximately $5 \mathrm{~mm} /$ hour.

The results of the varlous calculations are listed in Table $v$.

In summary, the visible energy radiated $(3900$ to 6900 A) per unit of length of lightning channel has been calculated using time-and wavelength-integrated spectrographic data of the 1965 lightning study. An estimated rain-transmission correction was used. The total energy deposition was calculated, assunting a dipole model of a lightning stroke and using measured values of charge transferred and channel lensth. The efficlency for conversion of electrical enerEy to visible radiation 18 found to be $0.007 \pm 36 \%$. 
Table V. Calculation of Efficlency

\begin{tabular}{ccc}
$\begin{array}{c}\text { Count } \\
\text { No. }\end{array}$ & $\begin{array}{c}\text { Stroke Time } \\
\text { after Trigger } \\
\text { (msec) }\end{array}$ & $\begin{array}{r}\text { Range } \\
\text { (km) }\end{array}$ \\
\cline { 1 - 1 } 87 & 87 & 10.0 \\
103 & 0 & 7.0 \\
103 & 49 & 7.0 \\
103 & 191 & 7.0 \\
127 & 74 & 7.2 \\
171 & 59 & 4.6 \\
186 & 152 & 4.0
\end{tabular}

$\begin{array}{ccccc}\begin{array}{c}\text { Rain } \\ \text { Transmission }\end{array} & \begin{array}{c}\text { Visible } \\ \text { Energy* } \\ \text { (joules }\end{array} & \begin{array}{c}\text { Energy } \\ \text { Deposited } \\ \text { (joules/meter) }\end{array} & \begin{array}{c}\text { Efficlency } \\ (\varepsilon)\end{array} \\ 8.7 \times 10^{-3} & 2.0 \times 10^{3} & & 3.3 \times 10^{5} & 6.1 \times 10^{-3} \\ 3.6 \times 10^{-2} & 5.6 \times 10^{2} & 5.1 \times 10^{4} & 1.1 \times 10^{-2} \\ 3.6 \times 10^{-2} & 4.2 \times 10^{2} & 4.0 \times 10^{4} & 1.1 \times 10^{-2} \\ 3.6 \times 10^{-2} & 5.7 \times 10^{2} & 9.0 \times 10^{4} & 6.4 \times 10^{-3} \\ 3.3 \times 10^{-2} & 2.3 \times 10^{2} & 3.2 \times 10^{4} & 7.3 \times 10^{-3} \\ 1.1 \times 10^{-1} & 2.2 \times 10^{2} & 2.1 \times 10^{4} & 1.1 \times 10^{-2} \\ 1.5 \times 10^{-1} & 5.9 \times 10^{2} & 2.2 \times 10^{4} & 2.6 \times 10^{-3}\end{array}$

Extinction Cofficient Due to Rainfall $=0.475 \mathrm{~km}^{-1}$. Welghted Average Efficlency $=0.007 \pm 36 \%$.

*Corrected for (1) humid-air trensmission and (2) estimated rainfall transmission.

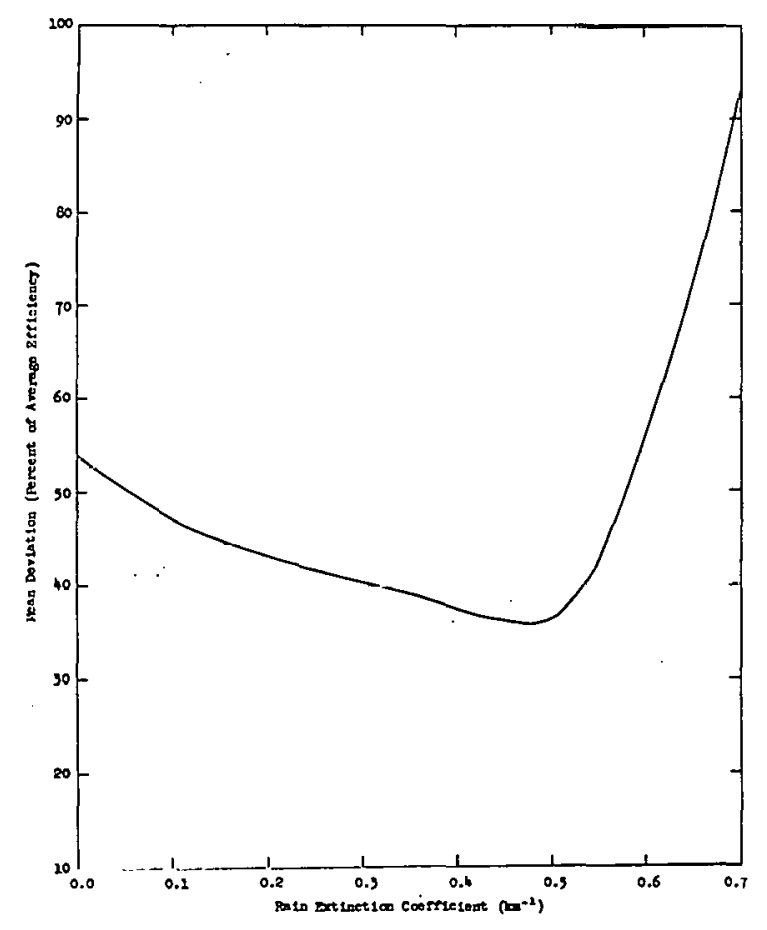

F1g. 26. Plot of mean deviation of efficlency vs rain extinction cofficient. The best eotimate of ralu oxtluitilun cuefrlelent for run 40 was chosen as that which infentmlzed the mean deviation.

\section{APFENDIX}

ATMOS FHERIC TRANSMISSION

1. The transmission of dry air is given by

$$
T_{a}=\exp \left[-\mu_{a}(\lambda) \frac{R}{8.01} \frac{P}{760} \frac{273}{T}\right],
$$

where $\mu_{a}(\lambda)$ is the wavelength-dependent extinction cœfflclent for molecular scattering, given by Allen; ${ }^{15} \mathrm{R}$ is the range of the lightning stroke in kilometers; $P$ is the partial pressure of air in Tarr; and $T$ is the temperature in degrees $\mathrm{K}$.

2. The transmission of water vapor is given by

$$
T_{w v}=\exp \left[-28.86 \mu_{w v}(\lambda)\left(\text { R.H.) } R \frac{E}{T}\right]\right. \text {, }
$$

where $\mu_{w v}(\lambda)$ is the wavelength-dependent extinction coefficient for water vapor, glven by Allen; ${ }^{15}$ R.H. 1s the relative humidity expressed as a decimal fraction; $R$ is the range of the stroke in k1lometers; and $E$ is the saturated water vapor pressure in Torr at temperature $T$ in degrees $K$.

The transmission of humid air is the product of $\mathrm{T}_{\mathrm{a}}$ and $\mathrm{T}_{\mathrm{wr}}$.

3. Transmission through rain whose drop diameter is laxger than $10 \mu$ is wavelength-independent in the visible, according to Middleton. ${ }^{18}$ The extinction coefficient for water drops is then given by $^{10}$ 
$\mu_{\mathrm{wd}}=2 \times 10^{5} \mathrm{~N} \pi \alpha^{2}\left(\mathrm{~km}^{-1}\right)$

where $N$ is the number density $\left(\mathrm{cm}^{-3}\right)$ of drops of radius $\alpha(\mathrm{cm})$.

Handy ${ }^{17}$ has published data on drop-81ze distr1butions for varlous rates of rainfall at flagstaff, Arizana. A rough numerical integration of extinction coefficlent over drop size distribition was carried out, and the resultant extinction coefficlent is plotted as a function of rain intensity in F18. 27.

\section{ACKOTOTEDGMENRS}

The program was carried out under the direction of Herman Hoerlin, and I thank him for the oppartun1ty to particlpate, and for his encouragement and suggestions. I also thank G. E. Barasch, K. B. M1tchell, H. M. Feek, and S. N. Stone without whose discussions, and help with spectrographic technique, my efforts would have been much less successful. Thanks are also due. L. M. Duncan for her effort in densitametry and the running of computer programs, to D." L. Stam for 1 lilustrations, to S. F. Waber for reducing the photogrephic ranging data, and to Barbara Anderson for her secretarlal work.

Th1s program is part of a DOD-ARPA and AEC-

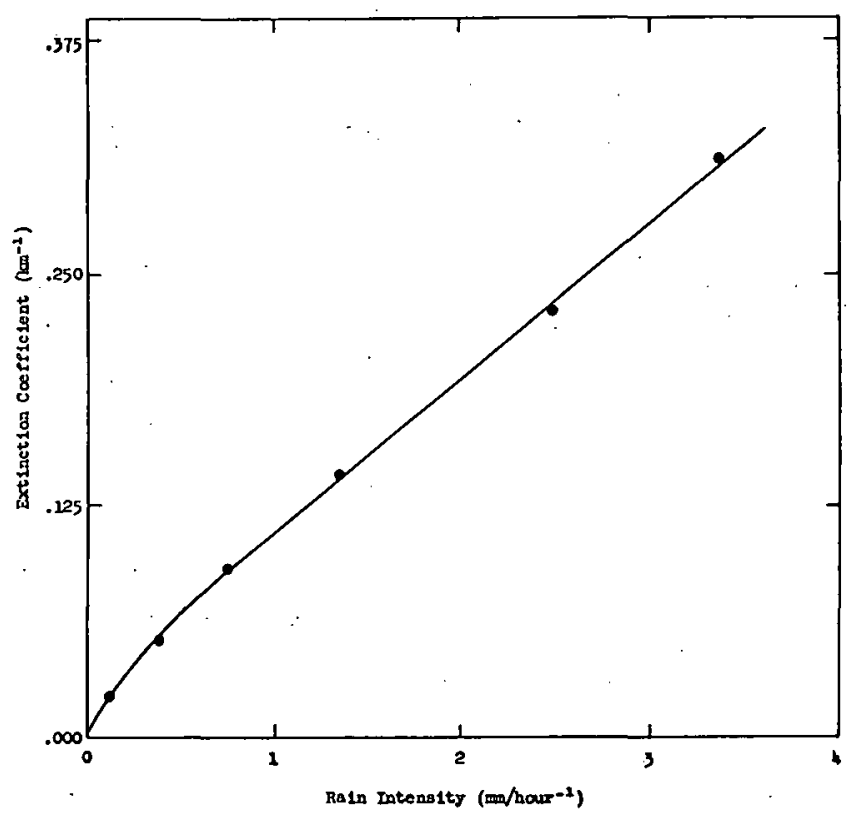

F1g. 27. Extinction cofficient for reindrops vs rain intensity as calculated by means of a rough numerical integration over raindrop size distribution published by Hardy.

sponsared effart to improve ground-based nuclear test detection capabilities. Thanks are also due It. Col. John H1Il and other personnel of the Nuclear Test Detection Division of ARPA for thetr active interest in the problems.

\section{REFFRENCES}

1. I. E. Salanave, Science 134, 1395 (1961).

2. P. Fox, Astrophys. J. 18, 294 (1903).

3. H. Israel and $\mathrm{K}$. Wurm, Naturwissenschaften 29, Heft 52 26.12, 778 (1941).

4. A. B. Melnel and L. E. Salanave, J. Atmos. Sci. 21, 157 (1964).

5. F. D. Harrington, "An $\mathrm{f} / 2.8$ Low-Dispersion TimeResolving Grating Spectrograph," IRL 5576, Feb. $7,1961$.

6. C. E. Mocre, NBS Tech. Note No. 36, Nov. 1959.

7. G. E. Baresch, "Lightning Study in Los Alamos Weather and Coodination Data," IASL Internal document, July 1, 1966.

8. ARPA Quarterly Repart, Apr11 1 - June 30, 1966, IASL Internal document, Augist 5, 1966.

9. L. E. Salanave, "The Fhotograph1c Spectrum of If ghtning; Determination of Channel Temperature from SIltless ispectra,". Problems of Atmospheric and Space Electric1ty, s. C. Corontt1, Ed., Elsevier Publishing Co., New Yark, 1965.
10. D. R. Westervelt and H. Hoerlin, Proc. IFHEE 53, 2067 (1965).

12. R. A. Amato, "Spectral and Temporal Characterist1cs of Lightning as Measured with Wide-Angle Detect or," Vol. I, EG\&G Tech. Report B-3506, March 1967.

12. D. J. Malan, Fhysics of Lightning, English Universities' Press, Ltd., Iondon, 1963.

13. N. K1tagawa and M. Brook, J. Geophys. Res: 65, 1189 (1960).

14. B. Fo Schonland, Atmospher1c Electric1ty, John W1ley \& Sons, Inc., New Yark, 1953.

15. C. W. Allen, Astrophysicel Quantities, axford Univ. Press, 1963, p. 122.

16. W. E. K. Middleton, Vision Through the Atmosphere, Univ. Toronto Press, 1958, p. 29.

17. K. K. Hardy, J. Atmos. Sc1. 20, 299 (1963)。 